\title{
A self-consistent, multivariate method for the determination of gas-phase rate coefficients, applied to reactions of atmospheric VOCs and the hydroxyl radical
}

\author{
Jacob T. Shaw ${ }^{1}$, Richard T. Lidster ${ }^{1, a}$, Danny R. Cryer ${ }^{2}$, Noelia Ramirez ${ }^{2}$, Fiona C. Whiting ${ }^{1}$, Graham A. Boustead ${ }^{2}$, \\ Lisa K. Whalley ${ }^{2,3}$, Trevor Ingham ${ }^{2,3}$, Andrew R. Rickard ${ }^{1,4}$, Rachel E. Dunmore ${ }^{1}$, Dwayne E. Heard ${ }^{2,3}$, \\ Ally C. Lewis ${ }^{1,4}$, Lucy J. Carpenter ${ }^{1}$, Jacqui F. Hamilton ${ }^{1}$, and Terry J. Dillon ${ }^{1}$ \\ ${ }^{1}$ Wolfson Atmospheric Chemistry Laboratories, Department of Chemistry, University of York, Heslington, \\ York, YO10 5DD, UK \\ ${ }^{2}$ School of Chemistry, University of Leeds, Leeds, LS2 9JT, UK \\ ${ }^{3}$ National Centre for Atmospheric Science, University of Leeds, Leeds, LS2 9JT, UK \\ ${ }^{4}$ National Centre for Atmospheric Science, University of York, Heslington, York, YO10 5DD, UK \\ ${ }^{a}$ now at: DSTL, Porton Down, Salisbury, Wiltshire, SP4 0JQ, UK
}

Correspondence: Jacqui F. Hamilton (jacqui.hamilton@york.ac.uk)

Received: 3 October 2017 - Discussion started: 6 October 2017

Revised: 5 February 2018 - Accepted: 12 February 2018 - Published: 22 March 2018

\begin{abstract}
Gas-phase rate coefficients are fundamental to understanding atmospheric chemistry, yet experimental data are not available for the oxidation reactions of many of the thousands of volatile organic compounds (VOCs) observed in the troposphere. Here, a new experimental method is reported for the simultaneous study of reactions between multiple different VOCs and $\mathrm{OH}$, the most important daytime atmospheric radical oxidant. This technique is based upon established relative rate concepts but has the advantage of a much higher throughput of target VOCs. By evaluating multiple VOCs in each experiment, and through measurement of the depletion in each VOC after reaction with $\mathrm{OH}$, the $\mathrm{OH}+\mathrm{VOC}$ reaction rate coefficients can be derived. Results from experiments conducted under controlled laboratory conditions were in good agreement with the available literature for the reaction of 19 VOCs, prepared in synthetic gas mixtures, with $\mathrm{OH}$. This approach was used to determine a rate coefficient for the reaction of $\mathrm{OH}$ with 2,3-dimethylpent-1-ene for the first time; $k=5.7( \pm 0.3) \times 10^{-11} \mathrm{~cm}^{3}$ molecule ${ }^{-1} \mathrm{~s}^{-1}$. In addition, a further seven VOCs had only two, or fewer, individual $\mathrm{OH}$ rate coefficient measurements available in the literature. The results from this work were in good agreement with those measurements. A similar dataset, at an elevated temperature of $323( \pm 10) \mathrm{K}$, was used to determine new $\mathrm{OH}$ rate coefficients for 12 aromatic, 5 alkane, 5 alkene and 3
\end{abstract}

monoterpene $\mathrm{VOC}+\mathrm{OH}$ reactions. In $\mathrm{OH}$ relative reactivity experiments that used ambient air at the University of York, a large number of different VOCs were observed, of which 23 were positively identified. Due to difficulties with detection limits and fully resolving peaks, only $19 \mathrm{OH}$ rate coefficients were derived from these ambient air samples, including 10 reactions for which data were previously unavailable at the elevated reaction temperature of $T=323( \pm 10) \mathrm{K}$.

\section{Introduction}

The atmosphere is an extremely complex and reactive mixture containing large numbers of inorganic and organic chemicals (Lewis et al., 2000; Goldstein and Galbally, 2007). Annually, over $1000 \mathrm{Tg}$ of volatile organic compounds (VOCs) are emitted to the troposphere from both anthropogenic and biogenic sources (Guenther et al., 2002). They have wide-ranging impacts on human health, either directly on inhalation or through their photochemical degradation cycles, which generate polluting and radiatively active secondary products such as ozone and aerosols. Atmospheric oxidative removal of most VOCs is mainly initiated by gasphase reaction with the hydroxyl radical $(\mathrm{OH})$. This pro- 
cess determines the tropospheric lifetime of an organic compound and often represents the rate-determining step in tropospheric ozone production and photochemical smog formation (Finalyson-Pitts and Pitts, 1997). Photochemical models used for air quality forecasting and future climate predictions can only attempt to represent these processes if provided with accurate rate coefficients for $\mathrm{OH}+\mathrm{VOC}$ reactions. Thus, this aspect of gas-phase kinetics represents a fundamental pillar of atmospheric and, more widely, environmental science (Burkholder et al., 2017).

Many hundreds of reactions for the $\mathrm{OH}$-initiated degradation of VOCs have been measured in the laboratory. However, many thousands more VOCs are emitted, or are formed in atmospheric photochemical oxidation, for which no $\mathrm{OH}$ kinetics have been measured. To bridge the gap between our limited experimental knowledge and the detailed chemical mechanisms required to describe the chemistry employed in air quality models, a number of methods have been developed to estimate rate coefficients for the reactions of $\mathrm{OH}$ with VOCs (Atkinson, 1986; Kwok and Atkinson, 1995; Ziemann and Atkinson, 2012). A structure-activity relationship (SAR) relates parameters such as the rate coefficient to the structural properties of chemical species, thereby providing a semiempirical method of parameter estimation which does not rely on experimentation. SARs are developed from datasets of experimentally derived parameters and therefore require accurate and reliable kinetic information from a wide range of organic reactions (in terms of both structure and functionality) to derive the various group rate coefficients and substituent factors needed (Calvert et al., 2002).

Almost all experimental $\mathrm{OH}+\mathrm{VOC}$ kinetic data used for atmospheric science have been determined via measurements conducted in controlled laboratory environments. Absolute methods for determining rate coefficients, such as flash photolysis and discharge flow, rely on accurate observations of the VOC concentration, which is maintained in large excess over that of OH (Pilling and Seakins, 1995). Much of the difficulty associated with these methods is related to the direct monitoring of the short-lived $\mathrm{OH}$ radical. Alternatively, the relative rate method requires neither an accurate knowledge of VOC concentration, nor direct monitoring of $\mathrm{OH}$ radicals (Atkinson, 1986). This technique instead relies on the simultaneous measurement of two species: a target VOC that is the focus of the investigation, and a well-characterised reference compound, which ideally possess similar rate coefficients for reaction with $\mathrm{OH}$. Upon exposure to $\mathrm{OH}$, these two VOCs are depleted relative to their individual rate coefficients. Thus, the ratio of their depletion allows for the calculation of the target rate coefficient, providing the $\mathrm{OH}+$ reference VOC rate coefficient is accurately known and the losses of both compounds in the reactive system are solely governed by reactions with $\mathrm{OH}$. Traditionally, both absolute and relative rate methods have been used to obtain rate coefficients for one $\mathrm{OH}+\mathrm{VOC}$ reaction at a time; as a result, these meth- ods are time consuming and few laboratories are capable of sustaining this type of fundamental science.

Whilst measured rate coefficients for reactions of $\mathrm{OH}$ with simple short-chain VOCs (up to seven carbon atoms) have been measured and evaluated at least once, and some many times over, data for many larger, more complex and multifunctional VOCs are often poorly constrained or unmeasured. Recent observations in a megacity demonstrate that VOCs containing more than seven carbon atoms can make up more than $50 \%$ of the local atmospheric hydrocarbon mass and dominate secondary organic aerosol (SOA) production (Dunmore et al., 2015). As the number of carbon atoms increases, so does the relative complexity of the oxidation reaction scheme, and hence the photochemical potential to form secondary pollutants such as ozone and SOA. As we discover more concerning the complexity of atmospheric VOC chemistry, the database for $\mathrm{OH}+\mathrm{VOC}$ rate coefficients appears increasingly deficient. Conventional laboratory methods, limited to studying a single VOC at a time, are no longer adequate and as such new approaches and techniques are required.

Comprehensive measurements of each individual $\mathrm{VOC}+\mathrm{OH}$ reaction rate coefficient can be avoided by using direct $\mathrm{OH}$ reactivity measurement techniques to measure the total $\mathrm{OH}$ reactivity sink. This parameter is equivalent to the inverse of the lifetime of the $\mathrm{OH}$ radical which can vary greatly depending on total VOC loading, from milliseconds in heavily polluted areas, to tens of seconds in clean air (Yang et al., 2016). Techniques using direct laser-induced fluorescence (LIF) detection of $\mathrm{OH}$ first identified a significant mismatch between measured and modelled OH reactivities (Kovacs et al., 2003; Di Carlo et al., 2004; Edwards et al., 2013). More recently, a technique that does not require the direct observation of $\mathrm{OH}$ radicals, termed the comparative reactivity method (CRM), has been developed (Sinha et al., 2008). It is thought that a lack of detailed compositional information and corresponding kinetic data for many $\mathrm{OH}+\mathrm{VOC}$ reactions may contribute to the so-called "missing reactivity" that has been observed both locally and globally (Lidster et al., 2014).

We describe here an experimental technique capable of measuring rate coefficients for large numbers of $\mathrm{OH}+\mathrm{VOC}$ reactions simultaneously, which builds upon a method employed by Kato et al. (2011) to measure the contribution of unidentified VOCs to $\mathrm{OH}$ reactivity. Coupling a conceptually simple and internally self-consistent relative rate kinetic method to modern automated analytical equipment allows for the study of a wide range of species, including some that are difficult to measure using more conventional methods. A subset of the existing $\mathrm{OH}+\mathrm{VOC}$ kinetic database is used to place the experimental relative rate data on an absolute scale, thereby reducing the reliance on a single reference reaction. A broad range of $\mathrm{OH}+\mathrm{VOC}$ reactions was studied, comparisons with the literature made and rate coefficients for pre- 
viously unmeasured $\mathrm{OH}+\mathrm{VOC}$ reactions determined at two reaction temperatures.

\section{Methodology}

Experiments were conducted under conditions of 1 bar $\left(\mathrm{N}_{2}\right)$ and $298-323 \mathrm{~K}$ in a stainless-steel flow reactor (approximate external dimensions $470 \times 25 \times 25 \mathrm{~mm}$, internal volume $250 \mathrm{~cm}^{3}$ ). A schematic of the apparatus is shown in Fig. 1. A quartz window, positioned on the top face of the reactor, allowed collimated vacuum-ultraviolet (VUV) light from a low-pressure $\mathrm{Hg} / \mathrm{Ar}$ lamp (L.O.T., Pen-Ray ${ }^{\circledR}$ ) to enter the tube. $\mathrm{N}_{2}\left(2000\right.$ standard $\mathrm{cm}^{3} \mathrm{~min}^{-1}$; $\mathrm{sccm}$ ) was passed through a bubbler filled with high purity water (Fischer, Optima grade) and supplied to the reactor upstream of the quartz window via a mass flow controller (MKS). $\mathrm{OH}$ was generated in the reaction chamber via the photolysis of $\mathrm{H}_{2} \mathrm{O}$ via Reaction (R1). Atomic $\mathrm{H}$ is rapidly converted to $\mathrm{HO}_{2}$ via Reaction (R2). The oxygen is found as impurities in the $\mathrm{N}_{2}$ carrier gas.

$\mathrm{H}_{2} \mathrm{O}+h v(184.95 \mathrm{~nm}) \rightarrow \mathrm{OH}+\mathrm{H}$

$\mathrm{H}+\mathrm{O}_{2}+\mathrm{M} \rightarrow \mathrm{HO}_{2}+\mathrm{M}$

The VOC mixture was introduced downstream of the quartz window via a stainless-steel injector (external diameter $3.2 \mathrm{~mm}$ ) to avoid unwanted removal of organics via photolysis. A sliding injector allowed for the optimisation of the inlet location with respect to both minimising the effects of VUV photolysis and maximising exposure to the short-lived OH radicals (Cryer, 2016). Mixing of the VOC flow (200$1000 \mathrm{sccm}$ ) with the main $\mathrm{OH} / \mathrm{H}_{2} \mathrm{O} / \mathrm{N}_{2}$ flow was aided by the injector design, which ensured that VOCs pass into the main body of the reactor via an array of four holes radially distributed about the injection tube. The flow of the VOC mixture and a secondary flow of $\mathrm{N}_{2}$ were controlled by two mass flow controllers (Tylan), allowing for the variation of VOC mixing ratio in the reactor. This meant that testing samples with a range in total $\mathrm{VOC}$ loading and $\mathrm{OH}$ reactivity was possible. A brief outline of the estimated range in total VOC concentrations and $\mathrm{OH}$ reactivity of each mixture injected into the reactor can be found in Table S1 in the Supplement. Assuming a constant total flow rate of $3000 \mathrm{sccm}$, the residence time of the VOCs in the reactor was calculated to be approximately $4 \mathrm{~s}$, of which $\mathrm{OH}$ is estimated to persist for no longer than $0.5 \mathrm{~s}$.

By alternating between the lamp switched off and the lamp switched on, a set of observations was generated that could be split into two unique datasets: those with $\mathrm{OH}$-initiated depletion and those without. Assuming consistent trapping and sampling with both the lamp switched off and the lamp switched on, the depletion of an individual VOC, with a known $\mathrm{OH}$ rate coefficient, can be evaluated using simple kinetic equations. This is shown using isoprene as an example in Eqs. (1), (2) and (3). The depletion factor in a VOC

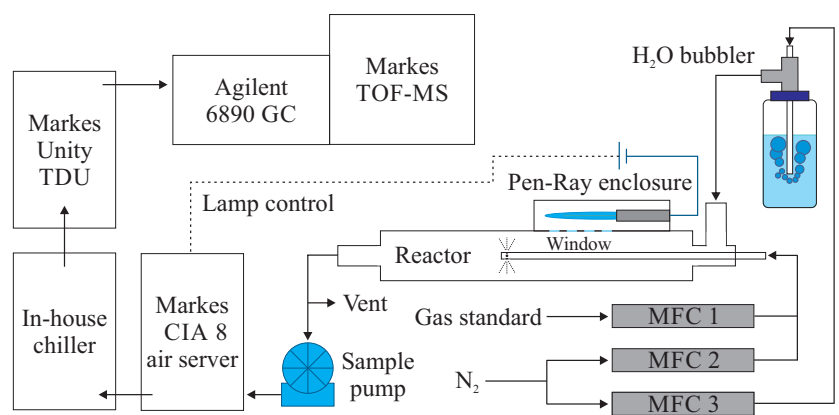

Figure 1. Schematic of the $\mathrm{OH}$ reactor configuration used. CIA 8 is the air server and canister interface accessory; GC is the gas chromatograph; MFC is the mass flow controller; TOF-MS is the time-of-flight mass spectrometer; TDU is the thermal desorption unit. The flow rate through MFC 1 was stepped from $200 \mathrm{sccm}$ to $1000 \mathrm{sccm}$ in $200 \mathrm{sccm}$ intervals. The combined flow rate through MFC 1 and MFC 2 was kept constant at $1000 \mathrm{sccm}$. The flow rate through MFC 3, and hence through the $\mathrm{H}_{2} \mathrm{O}$ bubbler, was set to $2000 \mathrm{sccm}$, resulting in a total flow through the reactor of $3000 \mathrm{sccm}$. The residence time of VOC inside the reactor after injection was approximately $4 \mathrm{~s}$, with the oxidation chemistry expected to occur in under $0.5 \mathrm{~s}$.

due to reaction with $\mathrm{OH}\left(\ln \left(\frac{[\mathrm{VOC}]_{0}}{[\mathrm{VOC}]}\right)\right)$ can be related to its rate coefficient, $k$, as shown in the example in Eq. (3).

isoprene $+\mathrm{OH} \stackrel{k_{3}}{\rightarrow}$ (products)

$\frac{\mathrm{d}[\text { isoprene }]}{\mathrm{d} t}=-k_{2}[$ isoprene $][\mathrm{OH}]$

$\frac{\mathrm{d}[\text { isoprene }]}{\text { [isoprene }]}=-k_{2}[\mathrm{OH}] \mathrm{d} t$

$\ln \left(\frac{[\text { isoprene }]_{0}}{[\text { isoprene }]_{\mathrm{t}}}\right)=k_{3} \int[\mathrm{OH}]_{\mathrm{t}} d \mathrm{t}$

The integral of $\mathrm{OH}$ concentration over time $\left(\int[\mathrm{OH}]_{\mathrm{t}} d \mathrm{t}\right)$ is known as the $\mathrm{OH}$ exposure $\left(\mathrm{OH}_{\exp }\right)$. The assumption is that all VOCs in the sample experience identical exposure to $\mathrm{OH}$ radicals due to rapid homogenous mixing in the reactor. However, because of the establishment of laminar flow in the reactor $(R e=132)$, thorough and complete mixing of $\mathrm{OH}$ is unlikely to take place (see the Supplement). When using reactive gas mixtures containing VOCs which react rapidly with $\mathrm{OH}$, a non-linear relationship between depletion factors and $k$ may therefore be observed (see the Supplement). However, this does not represent a limitation to the technique. So long as a relationship between $\ln \left(\frac{[\mathrm{VOC}]_{0}}{[\mathrm{VOC}]}\right)$ and $k$ can be characterised over a range of rate coefficients, and the data placed on an absolute scale, relative rate results can still be extracted.

Assuming that a relationship between $\ln \left(\frac{[\mathrm{VOC}]_{0}}{[\mathrm{VOC}]}\right)$ and $k$ can be identified, a previously unknown $\mathrm{OH}$ rate coefficient, 
$k_{X}$, for a specific target VOC, $X$, can be calculated using multiple known $k$ values as references. An unknown $\mathrm{OH}$ rate coefficient will be subject to less uncertainty if its value is interpolated rather than extrapolated and compounds at the extreme upper and lower limits of the observed relationship will be subject to greater uncertainty. Regardless, the use of multiple known $k$ values should reduce the reliance on any single reference reaction.

\subsection{Choice of reference $k$ values}

Some VOCs have literature measurements from two or more laboratories and these can differ considerably. The choice of different reference values for placing the relative rate measurements on an absolute scale can lead to variations in the final outcome of the experiment. When deciding on reference literature values for use in these experiments, a number of sources were utilised. The International Union of Pure and Applied Chemistry (IUPAC) Task Group on Atmospheric Chemical Kinetic Data Evaluation (http://iupac. pole-ether.fr/) provides recommended values for the reaction between $\mathrm{OH}$ and many short-chain hydrocarbons, along with some common monoterpene and aromatic VOCs (Atkinson et al., 2006). These values are evaluated using a balance of literature data and are updated regularly, and so these data were prioritised. Atkinson and Arey (2003) provide a reviewed dataset for a larger number of VOCs, collated from several sources, including the extensive evaluations on atmospheric oxidation of alkenes and atmospheric oxidation of aromatic hydrocarbons in Calvert et al. (2000, 2000), respectively. In the case that a reference value was not found in the IUPAC Kinetic Data Evaluation, Atkinson and Arey (2003) was used. Reference values at $298 \mathrm{~K}$ for only two compounds (1-nonene and 1-octene) could not be found in either the IUPAC-evaluated database or Atkinson and Arey (2003). Reference values for these compounds were therefore sourced from Aschmann and Atkinson (2008).

In some cases, the recommendations found in Calvert et al. $(2000,2002)$ were based upon a single relative rate experiment. The results of those experiments were often based upon outdated recommended rate coefficients for the reference compounds used. As such, and to ensure consistency, the reference values used in this work were updated to reflect any changes in the original relative rate compounds used in those experiments (see Tables 1, 2 and 3 for details).

Evaluated literature reference values for all the compounds used can be found in Tables 1, 2 and 3. The VOC depletion factor $\left(\ln \left(\frac{[\mathrm{VOC}]_{0}}{[\mathrm{VOC}]}\right)\right)$ was plotted against these literature values using a generalised form of Eq. (3) and weighted linear regression, using $\mathrm{QR}$ decomposition, performed to find the $\mathrm{OH}$ exposure $\left(\mathrm{OH}_{\text {exp }}\right)$.

\subsection{Gas sampling and analysis}

VOCs emerging from the reactor were collected using a Unity 2 thermal desorption unit (TDU) fitted with a Tenax TA sorbent trap and a CIA 8 Air Server attachment (Markes International). The system was pre-purged at a flow rate of $100 \mathrm{~cm}^{3} \mathrm{~min}^{-1}$ for 6 to $10 \mathrm{~min}$ before sampling. During sampling, the trap was maintained below $-20^{\circ} \mathrm{C}$ and a sampling flow rate of $100 \mathrm{~cm}^{3} \mathrm{~min}^{-1}$ used for $1 \mathrm{~min}$ to give a total sample volume of $100 \mathrm{~cm}^{3}$. After sampling, the system lines and sorbent trap were purged with helium carrier gas for $3 \mathrm{~min}$ at $100 \mathrm{~cm}^{3} \mathrm{~min}^{-1}$ to eliminate oxygen from the system before desorption onto the GC column. During the desorption process, the trap was rapidly heated to $250^{\circ} \mathrm{C}$ and held for $3 \mathrm{~min}$. All flow paths and sample lines were heated to $150^{\circ} \mathrm{C}$.

The GC system was an Agilent 6890 (Agilent Technologies) fitted with a DB5-MS ultra-inert capillary column $(60 \mathrm{~m} \times 0.32 \mathrm{~mm}$ ID $\times 1 \mu \mathrm{m}$ film, Agilent Technologies) coupled to a Markes International BenchTOF@ mass spectrometer. Column head pressure was set to $344 \mathrm{kPa}$ (50 psi) and operated in constant pressure mode using helium as a carrier gas. The temperature ramping of the GC oven was varied between mixtures to achieve optimum separation of VOCs. The GC method and TDU setup gave sample turnarounds of up to $70 \mathrm{~min}$ for more complex mixtures and up to $20 \mathrm{~min}$ for simpler mixtures.

\subsection{Synthetic mixtures}

Three synthetic gas mixtures were tested using the method outlined above, in which the compounds included in the mixtures, their preparation and the conditions under which they were tested differed. Differences in the reactivity of the VOCs within each mixture were distinguished by calculating the total $\mathrm{OH}$ reactivity for that mixture. The $\mathrm{OH}$ reactivity for each mixture was calculated as the total sum of each of the reference $k$ values multiplied by the VOC's concentration as shown in Eq. (4). This parameter is not necessary for the measurement of $k$ values but is provided in order to differentiate between individual mixtures and also between the same mixture studied under different flow regimes.

$\mathrm{OH}$ reactivity $=\sum k_{\mathrm{VOC}_{i}+\mathrm{OH}}\left[\mathrm{VOC}_{i}\right]$

Mixture 1 was prepared by injecting $1-5 \mathrm{~mm}^{3}$ of undiluted liquid VOC into a $500 \mathrm{~cm}^{3}$ evacuated, double-ended, stainless-steel sample cylinder (Swagelok). This cylinder was flushed into a pacified gas cylinder $(10 \mathrm{~L}$, Experis, Air Products) and filled to approximately 20 bar with $\mathrm{N}_{2}$. The cylinder was then evacuated to atmospheric pressure before being refilled to approximately 100 bar with $\mathrm{N}_{2}$ to achieve a final mixing ratio of each VOC in the cylinder of an estimated 30 parts per billion by volume (ppbv). Mixture 1 consisted of mainly monoterpenes, along with $m$ - and $o$-xylene (Table 1), and was studied at room temperature (average reaction $T=294.5( \pm 1.5) \mathrm{K})$. There was only a small range in 
Table 1. Results of relative rate experiments, with literature data, for each VOC in Mixture 1, ordered by measured $k$ value.

\begin{tabular}{|c|c|c|c|c|c|}
\hline Compound & $\begin{array}{r}\text { Range of } \\
\text { depletion/ } \\
\%\end{array}$ & $\begin{array}{r}\text { Measured } k(295 \mathrm{~K})^{\mathrm{a}} / \\
10^{-12} \mathrm{~cm}^{3} \\
\text { molecule }{ }^{-1} \mathrm{~s}^{-1}\end{array}$ & $\begin{array}{r}\text { Evaluated } \\
\text { literature } \\
k(298 \mathrm{~K}) / 10^{-12} \mathrm{~cm}^{3} \\
\text { molecule }{ }^{-1} \mathrm{~s}^{-1}\end{array}$ & Reference $^{\mathrm{b}}$ & $\begin{array}{r}\text { Number of } \\
\text { literature } \\
\text { measurements }\end{array}$ \\
\hline$\beta$-Ocimene & $27-70$ & $223 \pm 10$ & $245 \pm 49^{c}$ & Atkinson and Arey (2003) & 4 \\
\hline$\gamma$-Terpinene & $24-63$ & $207 \pm 6$ & $170\left(\begin{array}{l}+44 \\
-35\end{array}\right)$ & Atkinson et al. $(2006)^{\mathrm{d}}$ & 1 \\
\hline Myrcene & $24-62$ & $204 \pm 8$ & $209 \pm 42^{c}$ & Atkinson and Arey (2003) & 4 \\
\hline Limonene & $18-57$ & $152 \pm 4$ & $170 \pm 51$ & Atkinson and Arey (2003) & 5 \\
\hline Isoprene & $12-41$ & $104 \pm 6$ & $100\left(\begin{array}{l}+15 \\
-13\end{array}\right)$ & Atkinson et al. $(2006)^{\mathrm{d}}$ & $25+$ \\
\hline 3-Carene & $11-40$ & $97 \pm 4$ & $85 \pm 17^{c}$ & Atkinson and Arey (2003) & 2 \\
\hline$\beta$-Pinene & $9-34$ & $78 \pm 11$ & $79 \pm 20$ & Atkinson and Arey (2003) & 10 \\
\hline$\alpha$-Pinene & $7-24$ & $56 \pm 6$ & $53\left(\begin{array}{l}+22 \\
-15\end{array}\right)$ & Atkinson et al. (2006) ${ }^{\mathrm{d}}$ & 9 \\
\hline$m$-Xylene & $3-13$ & $22 \pm 6$ & $23 \pm 4$ & Atkinson and Arey (2003) & 15 \\
\hline$o$-Xylene & $2-7$ & $4.8 \pm 7$ & $13 \pm 3$ & Atkinson and Arey (2003) & 10 \\
\hline
\end{tabular}

${ }^{a}$ Errors are likely underestimated as they do not include the large uncertainties in the literature rate coefficients used as reference compounds. ${ }^{b}$ Data from Atkinson and Arey (2003) are collated from multiple sources including Calvert et al. $(2000,2002){ }^{c}$ Original result relative to 2,3-dimethylbut-2-ene; $k=1.13 \times 10^{-10} \mathrm{~cm}^{3}$ molecule ${ }^{-1} \mathrm{~s}^{-1}$. Updated result relative to $k=1.1( \pm 0.2) \times 10^{-10} \mathrm{~cm}^{3}$ molecule ${ }^{-1} \mathrm{~s}^{-1}$ as recommended in Calvert et al. (2002). ${ }^{\mathrm{d}}$ See also IUPAC Task Group on Atmospheric Chemical Kinetic Data Evaluation website - http://iupac.pole-ether.fr.

$\mathrm{OH}+\mathrm{VOC}$ rate coefficients and this mixture did not contain any compounds without a literature rate coefficient. The estimated total $\mathrm{OH}$ reactivity at standard temperature and pressure (STP) of the VOCs contained in Mixture 1 was $900 \mathrm{~s}^{-1}$. This mixture was diluted with $\mathrm{N}_{2}$ in differing amounts in order to inject gaseous samples into the reactor with a range of $\mathrm{OH}$ reactivities between 50 and $300 \mathrm{~s}^{-1}$.

Mixture 2 was prepared using the same method as that used for Mixture 1 and was also introduced into the reactor at room temperature $(294.5( \pm 1.5) \mathrm{K})$. The VOCs in this mixture comprised primarily 1-alkenes and cycloalkenes (Table 2) with a range of $\mathrm{OH}$ rate coefficients spanning less than a single order of magnitude. One compound, 2,3dimethylpent-1-ene, had no reported rate coefficient with $\mathrm{OH}$ at room temperature at the time of writing. The estimated total OH reactivity at STP of VOCs contained in Mixture 2 was $480 \mathrm{~s}^{-1}$. This mixture was diluted with $\mathrm{N}_{2}$ in differing amounts to inject gaseous samples into the reactor with a range of $\mathrm{OH}$ reactivities between 25 and $160 \mathrm{~s}^{-1}$.

Mixture 3 was prepared by adding between 1 and $5 \mu \mathrm{g}$, or $1 \mathrm{~mm}^{3}$, of each individual solid or liquid VOC to a $25 \mathrm{~cm}^{3}$ headspace vial. $200 \mathrm{~mm}^{3}$ of the mixture vapour was then added to a $500 \mathrm{~cm}^{3}$ evacuated, double-ended, stainless-steel sample cylinder (Swagelok). This cylinder was flushed into a pacified gas cylinder (Experis, Air Products) and filled to approximately 200 bar with ambient air using an oil-free, modified RIX compressor (RIX Industries). This mixture contained 43 species, grouped as biogenics, alkenes, alkanes and aromatics (Table 3). The vapour pressure of each compound was used to approximate its concentration in ppbv in the final mixture, to allow for an estimation of the total $\mathrm{OH}$ reactivity of the whole mixture of $380 \mathrm{~s}^{-1}$ (at STP). To facilitate consis- tent transmission of low-vapour-pressure VOCs through the reactor, Mixture 3 was introduced at an elevated temperature of $323( \pm 10) \mathrm{K}$. This temperature was achieved by wrapping the reactor in heat tape and was measured using a Type $\mathrm{K}$ mineral insulated thermocouple (TCDirect, $\mathrm{p} / \mathrm{n}$ 408-059) inserted into the reactor.

\section{Results and discussion}

Synthetic gas mixture results are presented in Sect. 3.1 and 3.2. Results taken from the more complex sampling of ambient air are presented in Sect. 3.3, along with an outline of the adjusted experimental setup. The errors, equal to $1 \sigma(66 \%)$, quoted on the measured values in this work, are the statistical uncertainties calculated by combining the instrument error and the scatter in the $\ln \left(\frac{[\mathrm{VOC}]_{0}}{[\mathrm{VOC}]}\right)$ vs. $k$ data. However, the uncertainties reported in the evaluated literature rate coefficients used as relative rate reference compounds are often large; up to $35 \%$ in some cases (Calvert et al., 2002). Using these values for the reference compounds therefore places a limitation on the precision of the results in this work that is not captured by the quoted uncertainties.

\subsection{Results from relative rate experiments at $295 \mathrm{~K}$}

Figure 2 shows sections of typical total ion chromatograms (TIC) obtained for Mixture 1: one chromatogram with the reactor lamp turned off (blue) and one for a sample with the reactor lamp turned on (black). When exposed to $\mathrm{OH}$ radicals (black), there is a clear reduction in the observed concentration of all VOCs present, reflected in the reduction in peak areas compared with the lamp off (blue). The use of 
Table 2. Results of relative rate experiments, with literature data, for each VOC in Mixture 2, ordered by measured $k$ value.

\begin{tabular}{|c|c|c|c|c|c|}
\hline Compound & $\begin{array}{r}\text { Range of } \\
\text { depletion/ } \\
\%\end{array}$ & $\begin{array}{r}\text { Measured } \\
k(295 \mathrm{~K})^{\mathrm{a}} / \\
10^{-12} \mathrm{~cm}^{3} \\
\text { molecule }{ }^{-1} \mathrm{~s}^{-1}\end{array}$ & $\begin{array}{r}\text { Evaluated } \\
\text { literature } \\
k(298 \mathrm{~K}) / \\
10^{-12} \mathrm{~cm}^{3} \\
\text { molecule }{ }^{-1} \mathrm{~s}^{-1}\end{array}$ & Reference $^{b}$ & $\begin{array}{r}\text { Number of } \\
\text { literature } \\
\text { measurements }\end{array}$ \\
\hline Isoprene & $8-26$ & $103 \pm 5$ & $100\left(\begin{array}{l}+15 \\
-13\end{array}\right)$ & Atkinson et al. $(2006)^{\mathrm{d}}$ & $25+$ \\
\hline$\beta$-Pinene & $5-21$ & $75 \pm 12$ & $79 \pm 20$ & Atkinson and Arey (2003) & 10 \\
\hline Cycloheptene & $6-20$ & $74 \pm 10$ & $74 \pm 10^{\mathrm{c}}$ & Atkinson and Arey (2003) & 1 \\
\hline Cyclohexene & $6-20$ & $71 \pm 4$ & $68 \pm 17$ & Atkinson and Arey (2003) & 9 \\
\hline Cyclopentene & $7-19$ & $69 \pm 9$ & $67 \pm 23$ & Atkinson and Arey (2003) & 3 \\
\hline 2,3-dimethylpent-1-ene & $5-17$ & $57 \pm 3$ & & & \\
\hline$\alpha$-Pinene & $4-17$ & $53 \pm 4$ & $53\left(\begin{array}{l}+22 \\
-15\end{array}\right)$ & Atkinson et al. (2006) ${ }^{\mathrm{d}}$ & 9 \\
\hline 1-Octene & $4-15$ & $44 \pm 5$ & $41.4 \pm 0.8$ & Aschmann and Atkinson (2008) & 2 \\
\hline 1-Nonene & $4-15$ & $41 \pm 3$ & $43.2 \pm 0.5$ & Aschmann and Atkinson (2008) & 2 \\
\hline 1-Heptene & $3-13$ & $36 \pm 4$ & $40 \pm 12$ & Atkinson and Arey (2003) & 2 \\
\hline 1-Hexene & $2-15$ & $46 \pm 12$ & $37 \pm 11$ & Atkinson and Arey (2003) & 2 \\
\hline
\end{tabular}

${ }^{a}$ Errors are likely underestimated as they do not include the large uncertainties in the literature rate coefficients used as reference compounds. ${ }^{\mathrm{b}}$ Data from Atkinson and Arey (2003) are collated from multiple sources including Calvert et al. $(2000,2002){ }^{\mathrm{c}}$ Original result relative to isoprene; $k=1.01 \times 10^{-10} \mathrm{~cm}^{3} \mathrm{molecule}-1 \mathrm{~s}^{-1}$. Updated result relative to $k=1.00\left({ }_{-0.13}^{+0.15}\right) \times 10^{-10} \mathrm{~cm}^{3}$ molecule ${ }^{-1} \mathrm{~s}^{-1}$ as recommended by Atkinson et al. (2006). ${ }^{\mathrm{d}}$ See also IUPAC Task Group on Atmospheric Chemical Kinetic Data Evaluation website - http://iupac.pole-ether.fr.

selected ion chromatograms provides a clear advantage of using a time-of-flight mass spectrometer (TOF-MS) over a less specific detector due to the reduction in background interference and ease of peak identification. Peak areas were analysed automatically using peak integration software (Agilent Technologies) with appropriate mass ion selection for each VOC. This allowed for the complete separation of peaks which may otherwise have been unresolved.

To ensure that the observed depletion in each VOC's concentration was entirely due to reaction with $\mathrm{OH}$, experiments were performed in the absence of the $\mathrm{OH}$ precursor (i.e. the water bubbler was removed from the system). When the lamp was switched on, there was no significant deviation observed in the peak areas for any of the VOC used. As a result, both direct photolysis of VOC and unwanted perturbations due to the lamp (such as heating effects) were deemed to be negligible. However, other possible perturbations, such as those due to reaction of the VOCs with other photooxidants, could not be ruled out using this method.

Experiments were conducted on each VOC mixture using different mass flow controller settings, allowing for the injection of mixtures into the reactor with five different total VOC loadings and hence five different total $\mathrm{OH}$ reactivities. GC-MS data were analysed using automatic peak integration software and outlying peak areas recommended and removed using the $\mathrm{MAD}_{e}$ method (Burke, 2001).

Figure 3 shows the relationship between experimentally observed $\ln \left(\frac{[\mathrm{VOC}]_{0}}{[\mathrm{VOC}]}\right)$ and literature rate coefficients for Mixture 1 with an $\mathrm{OH}$ reactivity of $240 \mathrm{~s}^{-1}$. A clear correlation between $k$ and $\ln \left(\frac{[\mathrm{VOC}]_{0}}{[\mathrm{VOC}]}\right)$ can be seen $\left(R^{2}=0.96\right)$. The na-

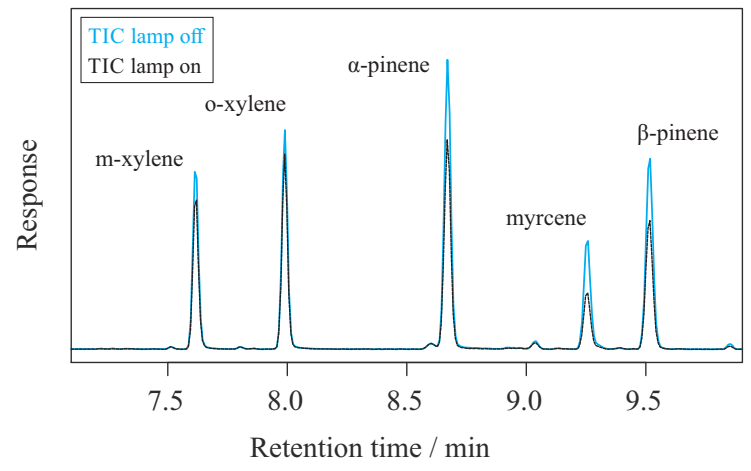

Figure 2. Typical total ion chromatograms (TICs) obtained for a ppbv mixing ratio gas standard (Mixture 1) with the lamp off (blue) and lamp on (black). Greater differences in peak areas are observed for VOCs which react faster with $\mathrm{OH}$. Literature rate coefficients (in units of $10^{-12} \mathrm{~cm}^{3}$ molecule ${ }^{-1} \mathrm{~s}^{-1}$ ) for the VOCs are $m$-xylene ${ }^{1}, 23( \pm 4) ; o$-xylene ${ }^{1},(13 \pm 3) ; \alpha$-pinene ${ }^{2},\left(53_{-15}^{+22}\right)$; myrcene $^{1}, 209 \pm(42)$; and $\beta$-pinene ${ }^{1}, 79 \pm(20) .{ }^{1}$ Atkinson and Arey (2003) updated to reflect changes in reference compound. ${ }^{2}$ Atkinson et al. (2006) - http://iupac.pole-ether.fr/.

ture of Eq. (3) suggests that the fit should be proportional, with an intercept of zero. However, despite the intercept lying close to zero, linear fits with a non-zero intercept were found to be a more appropriate approximation across the range of $k$ values measured. Extrapolation beyond the range of reference $\mathrm{OH}+\mathrm{VOC} k$ values is not necessary to make accurate measurements of $k$ values. For the calculation to be valid, there needs only to be a consistent relationship between the 
Table 3. Results of relative rate experiments, with literature data, for each VOC in Mixture 3, ordered by curve measured $k$ value.

\begin{tabular}{|c|c|c|c|c|c|c|c|}
\hline Group & Compound & $\begin{array}{r}p_{0}^{\mathrm{a}} / \\
\mathrm{mmHg}\end{array}$ & $\begin{array}{r}\text { Estimated } \\
\text { cylinder } \\
\text { concentration/ } \\
\mathrm{ppb}\end{array}$ & $\begin{array}{r}\text { Linear } \\
\text { measured } \\
k(323 \mathrm{~K}) / \\
10^{-12} \mathrm{~cm}^{3} \\
\text { molecule }{ }^{-1} \mathrm{~s}^{-1}\end{array}$ & $\begin{array}{r}\text { Curve } \\
\text { measured } \\
k(323 \mathrm{~K}) / \\
10^{-12} \mathrm{~cm}^{3} \\
\text { molecule }{ }^{-1} \mathrm{~s}^{-1}\end{array}$ & $\begin{array}{r}\text { Literature } \\
k 323 \mathrm{~K} / \\
10^{-12} \mathrm{~cm}^{3} \\
\text { molecule } \mathrm{e}^{-1} \mathrm{~s}^{-1}\end{array}$ & $\begin{array}{r}\text { Evaluated } \\
\text { literature } k 298 \mathrm{~K} / \\
10^{-12} \mathrm{~cm}^{3} \\
\text { molecule }{ }^{-1} \mathrm{~s}^{-1}\end{array}$ \\
\hline \multirow[t]{9}{*}{ Biogenics } & $\beta$-Ocimene & 1.60 & 0.23 & & $950 \pm 800$ & $261\left(\begin{array}{l}+54 \\
-48\end{array}\right)^{\mathrm{e}}$ & $245 \pm 49^{\mathrm{b}}$ \\
\hline & Myrcene & 2.09 & 0.31 & & $310 \pm 105$ & $253\left(\begin{array}{c}+68 \\
-56\end{array}\right)^{\mathrm{d}}$ & $209 \pm 42^{\mathrm{b}}$ \\
\hline & $\gamma$-Terpinene & 1.10 & 0.16 & & $180 \pm 19$ & & $170\left(\begin{array}{l}+44 \\
-35\end{array}\right)^{\mathrm{c}}$ \\
\hline & Limonene & 1.98 & 0.29 & & $140 \pm 5$ & $148\left(\begin{array}{l}+21 \\
-18\end{array}\right)^{b}$ & $170 \pm 51^{b}$ \\
\hline & 3-Carene & 1.90 & 0.28 & & $81 \pm 1$ & & $85 \pm 17^{b}$ \\
\hline & $\beta$-Pinene & 2.93 & 0.43 & & $81 \pm 20$ & $66\left(\begin{array}{c}+11 \\
-9.4\end{array}\right){ }^{b}$ & $79 \pm 20^{\mathrm{b}}$ \\
\hline & Isoprene & 550 & 80.4 & & $75 \pm 8$ & $90\left(\begin{array}{l}+33 \\
-24\end{array}\right)^{c}$ & $100\left({ }_{-13}^{+15}\right)^{\mathrm{c}}$ \\
\hline & $\alpha$-Pinene & 4.75 & 0.69 & $48 \pm 4$ & $50 \pm 2$ & $47\left(\begin{array}{l}+8.3 \\
-7.0\end{array}\right)^{\mathrm{c}}$ & $53\left(\begin{array}{l}+22 \\
-15\end{array}\right)^{\mathrm{c}}$ \\
\hline & Camphene & 2.50 & 0.37 & $47 \pm 3$ & $50 \pm 2$ & & $53 \pm 7^{b}$ \\
\hline \multirow[t]{5}{*}{ Alkenes } & Cycloheptene & 22.5 & 3.29 & & $71 \pm 4$ & & $74 \pm 10^{b}$ \\
\hline & Cyclopentene & 378 & 55.3 & $53 \pm 3$ & $58 \pm 1$ & & $67 \pm 23^{b}$ \\
\hline & Cyclohexene & 89.0 & 13.0 & $53 \pm 5$ & $57 \pm 4$ & & $68 \pm 17^{b}$ \\
\hline & 1-Hexene & 184 & 26.9 & $33 \pm 6$ & $31 \pm 5$ & & $37 \pm 11^{\mathrm{b}}$ \\
\hline & 1-Heptene & 59.3 & 8.67 & $18 \pm 2$ & $18 \pm 1$ & & $40 \pm 12^{b}$ \\
\hline \multirow[t]{13}{*}{ Alkanes } & Cyclooctane & 4.60 & 0.67 & $17 \pm 1$ & $17.4 \pm 0.5$ & $15\left(\begin{array}{c}+8 \\
-5\end{array}\right)^{b}$ & $13 \pm 0.4^{b}$ \\
\hline & Cycloheptane & 21.6 & 3.16 & $14 \pm 2$ & $15 \pm 1$ & $13\left(\begin{array}{c}+6 \\
-4\end{array}\right)^{b}$ & $12 \pm 3^{b}$ \\
\hline & Ethylcyclohexane & 31.0 & 4.54 & $15 \pm 1$ & $15 \pm 1$ & & \\
\hline & 3-Methylheptane & 19.6 & 2.87 & $13 \pm 3$ & $14 \pm 2$ & & \\
\hline & $n$-Decane & 1.43 & 0.21 & $13 \pm 2$ & $14 \pm 1$ & $12\left(\begin{array}{c}+2 \\
-1.9\end{array}\right)^{b}$ & $11 \pm 2^{\mathrm{b}}$ \\
\hline & $n$-Nonane & 4.45 & 0.65 & $14 \pm 2$ & $14 \pm 1$ & $10\left(\begin{array}{c}+1.1 \\
-1.0\end{array}\right)^{b}$ & $10 \pm 1.9^{b}$ \\
\hline & 2-Methylheptane & 20.5 & 3.00 & $12 \pm 1$ & $12.2 \pm 0.2$ & & \\
\hline & 2-Methylpentane & 211 & 30.8 & $11 \pm 3$ & $12 \pm 2$ & & $5.2 \pm 1.3^{b}$ \\
\hline & 3-Methylpentane & 190 & 27.8 & $8.7 \pm 1.1$ & $9.1 \pm 0.9$ & & $5.2 \pm 1.3^{b}$ \\
\hline & $n$-Octane & 14.1 & 2.06 & $7.8 \pm 1.8$ & $8.8 \pm 1.4$ & $8.7\left(\begin{array}{c}+2 \\
-1.7\end{array}\right)$ & $8.1 \pm 1.6^{b}$ \\
\hline & $n$-Heptane & 46.0 & 6.73 & $8.3 \pm 0.8$ & $7.9 \pm 0.5$ & $7.2\left(\begin{array}{c}+2 \\
-1.6\end{array}\right)^{b}$ & $6.8 \pm 1.4^{\mathrm{b}}$ \\
\hline & 2,2,3-Trimethylbutane & 90.0 & 13.2 & $4.6 \pm 1.9$ & $6.3 \pm 2.0$ & $4.0\left({ }_{-1.2}^{+1.7}\right)^{\mathrm{b}}$ & $3.8 \pm 1.0^{\mathrm{b}}$ \\
\hline & 3-Ethyltoluene & 3.00 & 0.44 & $34 \pm 1$ & $34 \pm 1$ & & $19 \pm 7^{b}$ \\
\hline \multirow[t]{13}{*}{ Aromatics } & 1,2,4-Trimethylbenzene & 2.10 & 0.31 & $32 \pm 2$ & $32 \pm 1$ & & $33 \pm 8^{b}$ \\
\hline & 1,2,3-Trimethylbenzene & 1.69 & 0.25 & $32 \pm 1$ & $31 \pm 1$ & & $33 \pm 8^{\mathrm{b}}$ \\
\hline & Naphthalene & 0.085 & 0.01 & $22 \pm 1$ & $22 \pm 1$ & $22.4^{\mathrm{b}}$ & $23 \pm 6^{\mathrm{b}}$ \\
\hline & $m$-Xylene & 8.29 & 1.21 & $21 \pm 2$ & $21 \pm 1$ & & $23 \pm 4^{b}$ \\
\hline & Indane & 1.50 & 0.22 & $19 \pm 1$ & $19 \pm 1$ & & $19 \pm 8^{\mathrm{b}}$ \\
\hline & 4-Ethyltoluene & 2.90 & 0.42 & $16 \pm 1$ & $15.6 \pm 0.1$ & & $12 \pm 4^{\mathrm{b}}$ \\
\hline & 2-Ethyltoluene & 2.60 & 0.38 & $15 \pm 1$ & $15 \pm 1$ & & $12 \pm 4^{\mathrm{b}}$ \\
\hline & $o$-Xylene & 6.61 & 0.97 & $12 \pm 1$ & $13 \pm 1$ & & $13 \pm 3^{b}$ \\
\hline & 4-Isopropyltoluene & 1.50 & 0.22 & $12 \pm 1$ & $12 \pm 1$ & & $14 \pm 3^{\mathrm{b}, \mathrm{f}}$ \\
\hline & $n$-Propylbenzene & 4.50 & 0.66 & $8.6 \pm 0.9$ & $8.5 \pm 0.5$ & & $5.8 \pm 1.5^{\mathrm{b}}$ \\
\hline & Isopropylbenzene & 4.50 & 0.66 & $6.2 \pm 1.5$ & $7.2 \pm 1.0$ & & $6.3 \pm 2^{\mathrm{b}}$ \\
\hline & Ethylbenzene & 9.60 & 1.40 & $6.2 \pm 1.3$ & $7.0 \pm 1.0$ & & $7.0 \pm 2^{b}$ \\
\hline & Toluene & 28.4 & 4.15 & $5.0 \pm 0.5$ & $5.1 \pm 0.3$ & $5.2\left(\begin{array}{l}+4 \\
-2\end{array}\right)^{\mathrm{c}}$ & $5.6\left({ }_{-1.2}^{+1.5}\right)^{\mathrm{c}}$ \\
\hline
\end{tabular}

${ }^{\mathrm{a}} p_{0}$ refers to the vapour pressure of the VOC. This was used to estimate the concentration of VOCs transferred to the cylinder. ${ }^{\mathrm{b}}$ Atkinson and Arey (2003). ${ }^{\mathrm{c}}$ Atkinson et al. (2006) (see also IUPAC Task Group on Atmospheric Chemical Kinetic Data Evaluation website - http://iupac.pole-ether.fr). ${ }^{\mathrm{d}}$ Hites and Turner (2009). ${ }^{\mathrm{e}}$ Kim et al. (2011). ${ }^{\mathrm{f}}$ Original result relative to cyclohexane; $k=7.14 \times 10^{-12} \mathrm{~cm}^{3}$ molecule $\mathrm{s}^{-1}$. Updated result relative to $k=6.97( \pm 1.4) \times 10^{-12} \mathrm{~cm}^{3}$ molecule $\mathrm{s}^{-1} \mathrm{~s}^{-1}$ as recommended by Atkinson and Arey (2003). 


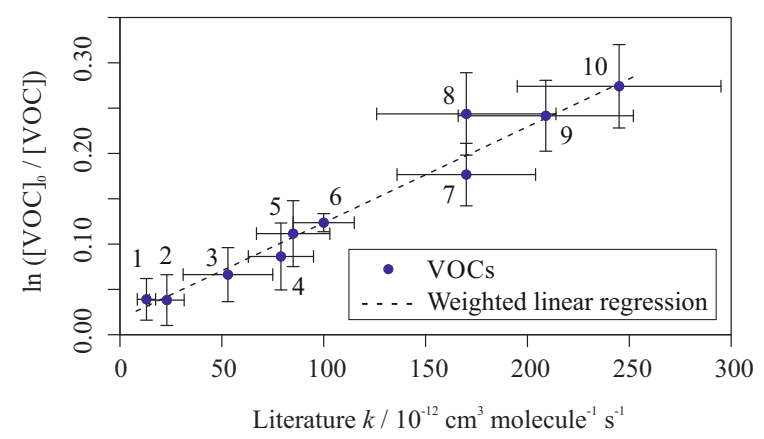

Figure 3. Relative rate plot for Mixture 1 ( $\mathrm{OH}$ reactivity is $240 \mathrm{~s}^{-1}$ ) at $295 \mathrm{~K}$. Compounds with a known rate coefficient are plotted using literature values. Error bars on the $y$ axis, equal to 1 standard error, are calculated by combining the standard error in peak areas for six lamp-off samples and six lamp-on samples. Error bars on the $x$ axis are typically large (approximately $\pm 20-30 \%$ ) and account for deviations from the line. A weighted (to the uncertainty in the $y$ values) linear fit was used to generate the slope with a value of $\mathrm{OH}_{\exp }=1.1( \pm 0.07) \times 10^{9}$ molecules $\mathrm{cm}^{-3} \mathrm{~s}$ and $R^{2}$ of 0.96 . Identities of VOCs: 1, $o$-xylene; $2, m$-xylene; $3, \alpha$-pinene; 4 , $\beta$-pinene; 5 , 3-carene; 6 , isoprene; 7, limonene; $8, \gamma$-terpinene; 9 , myrcene; $10, \beta$-ocimene.

depletion factor for each VOC and $k$. For Mixture 1 with a low $\mathrm{OH}$ reactivity $\left(50 \mathrm{~s}^{-1}\right)$, a three-parameter exponential distribution function, given in Eq. (5), was used to fit the data, shown in Fig. 4. Whilst this is inconsistent with Eq. (3), it does not necessarily detract from the relative rate nature of the experiment, as a reliable and consistent function can still be plotted through the data. This type of distribution possibly occurs when gas mixtures contain low concentrations of very fast reacting VOCs and arises due to poor mixing conditions within the reactor (see the Supplement). As this was only observed during some experiments, the relative rate data obtained from these plots were disregarded.

$y=e^{a+\frac{b}{x+c}}$

The gradient of the line in Fig. 3 is $\mathrm{OH}_{\text {exp }}$, the integral of $\mathrm{OH}$ concentration over time (see Eq. 3). $\mathrm{OH}_{\exp }$ decreased with the increasing $\mathrm{OH}$ reactivity of the gas mixture injected (see Fig. S6 in the Supplement).

By referring to a generalised version of Eq. (3), and using the function of the weighted linear regression, it is possible to estimate new $k$ values at room temperature $(295( \pm 2) \mathrm{K})$ for all components in Mixture 1 relative to each other. $\mathrm{As} \mathrm{OH}_{\text {exp }}$ is dependent on the $\mathrm{OH}$ reactivity of the mixture introduced into the reactor, it is necessary to produce a $k$ value for each VOC at each mass flow controller setting. An error-weighted mean of the individual $k$ values determined at each $\mathrm{OH}_{\text {exp }}$ was then used to assign a final measured $\mathrm{OH}$ rate coefficient for each VOC in the mixture (Table 1).

The majority of VOCs show rate coefficients consistent with those in our evaluated literature dataset, within experi-

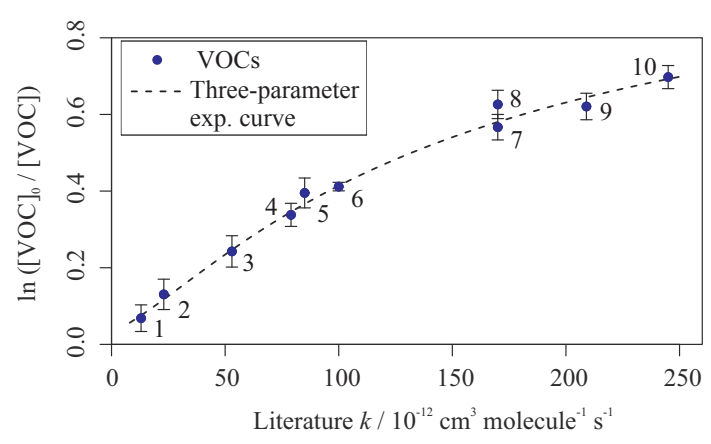

Figure 4. Relative rate plot for Mixture $1\left(\mathrm{OH}\right.$ reactivity is $\left.50 \mathrm{~s}^{-1}\right)$ at $295 \mathrm{~K}$. Compounds with a known rate coefficient are plotted using literature values. Error bars on the $y$ axis, equal to 1 standard error, are calculated by combining the standard error in peak areas for six lamp-off samples and six lamp-on samples. Error bars on the $x$ axis are not displayed for reasons of clarity but are typically large (approximately $\pm 20-30 \%$ ) and account for deviations from the line. The black dashed line shows the relationship observed when VOC concentrations are low, modelled by a three-parameter exponential curve (see the Supplement). Identities of VOCs: 1, $o$ xylene; $2, m$-xylene; $3, \alpha$-pinene; $4, \beta$-pinene; 5 , 3 -carene; 6 , isoprene; 7 , limonene; $8, \gamma$-terpinene; 9 , myrcene; $10, \beta$-ocimene.

mental error and literature uncertainty. Thus, this technique represents an extension of the classical relative rate experiment but with the advantage of using multiple species to generate a multivariate, self-consistent relationship between the depletion in a VOC and its rate coefficient for reaction with $\mathrm{OH}$, rather than using just one pair of compounds at a time (reactant plus reference). By using multiple reference compounds, the risk of a single erroneous reference value perturbing the rest of the data is reduced, assuming that all compounds behave in a similar way upon exposure to $\mathrm{OH}$. This advantage does come at the expense of a loss in traceability; when changes are made to the reference rate coefficient for a specific measurement, it is relatively easy to propagate the uncertainty change to the relative rate measurements. When using multiple reference reactions, and generating a relationship between them, the transfer of an updated rate coefficient change would obviously be more complicated.

Whilst the majority of our data are in good agreement with the internally consistent literature dataset, the wider literature contains rate coefficient measurements for many of the compounds not included in the IUPAC evaluations or the review paper, Atkinson and Arey (2003). For example, a recent measurement of the oxidation of $\beta$-ocimene by $\mathrm{OH}$ provided a rate coefficient of $236( \pm 54) \times 10^{-12} \mathrm{~cm}^{3}$ molecule ${ }^{-1} \mathrm{~s}^{-1}$, which is in good agreement with our own result for the same reaction, of $223( \pm 10) \times 10^{-12} \mathrm{~cm}^{3}$ molecule ${ }^{-1} \mathrm{~s}^{-1}$ (Gaona-Colmán et al., 2016). Recent relative rate measurements of the $\mathrm{OH}+$ myrcene reaction by Hites and Turner (2009) and Kim et al. (2011) are $50 \%$ greater than that calculated in this work. However, their measurements of $335\left({ }_{-101}^{+144}\right)$ and $334\left({ }_{-132}^{+220}\right) \times 10^{-12} \mathrm{~cm}^{3}$ molecule ${ }^{-1} \mathrm{~s}^{-1}$, 
respectively, have exceptionally large uncertainties that encompass the measurement presented in this paper, of 206 $( \pm 8) \times 10^{-12} \mathrm{~cm}^{3}$ molecule ${ }^{-1} \mathrm{~s}^{-1}$. Our measurement of the rate coefficient for the reaction of limonene with $\mathrm{OH}$ is also in good agreement with the recent value in Braure et al. (2014), of $165( \pm 25) \times 10^{-12} \mathrm{~cm}^{3}$ molecule $\mathrm{s}^{-1} \mathrm{~s}^{-1}$.

The measured rate coefficient for the $\mathrm{OH}+\mathrm{o}$-xylene reaction, of $4.8( \pm 7) \times 10^{-12} \mathrm{~cm}^{3}$ molecule ${ }^{-1} \mathrm{~s}^{-1}$, is the only result which is not totally consistent with the literature. It is likely that this anomaly arose due to $o$-xylene being at the lower extreme of the mixture reactivity. It was therefore removed from subsequent analyses.

Figure 5 shows an example relative rate plot for Mixture 2, for which a linear relationship is observed across all $\mathrm{OH}$ reactivities tested. $k$ values for all the VOCs in this mixture can be estimated using the generalised form of Eq. (3). These values are given in Table 2 and are all consistent with our evaluated literature dataset, whereas other literature measurements for the $\mathrm{OH}+$ cyclohexene and the $\mathrm{OH}+$ cyclopentene reactions, of $54 \times 10^{-12}$ and $45 \times 10^{-12} \mathrm{~cm}^{3}$ molecule ${ }^{-1} \mathrm{~s}^{-1}$, respectively, are much smaller than our own estimations (Rogers, 1989). Figure 6 demonstrates that our measured rate coefficients for the reactions of $\mathrm{OH}$ with 1-alkenes agree well with both experimentally derived literature rate coefficients and those estimated from structure activity relationships. Whilst we do not observe a strictly linear trend between $k$ values and increasing carbon chain length for the 1-alkenes, most of our measurements lie between the SAR predictions of Kwok and Atkinson (1995), Peeters et al. (1999, 2007) and Nishino et al. (2009), and are in good agreement with other experimental measurements.

Mixture 3 contained a much broader range in VOCs, both in terms of functionality and structure, but also in terms of $k$ values. Unlike Mixtures 1 and 2, the values for $k$ spanned almost 2 orders of magnitude, from slow-reacting alkanes such as $n$-heptane, literature $k=7.2\left({ }_{-1.6}^{+2.0}\right) \times 10^{-12} \mathrm{~cm}^{3}$ molecule ${ }^{-1} \mathrm{~s}^{-1}$, to faster reacting monoterpenes such as limonene, literature $k=170$ $( \pm 51) \times 10^{-12} \mathrm{~cm}^{3}$ molecule ${ }^{-1} \mathrm{~s}^{-1}$ (Atkinson and Arey, 2003). The concentrations of the individual VOCs in the mixture were also much lower compared with the other mixtures. Both the complexity of the mixture and the low concentration of the constituents make this mixture more representative of ambient atmospheric conditions. This mixture was studied at an elevated reactor temperature of $T=323( \pm 10) \mathrm{K}$ in order to avoid greater uncertainties as a result of partitioning of the less-volatile VOCs to the reactor surfaces.

Figure 7 shows the results of a relative rate experiment for Mixture 3. Only compounds with a known rate coefficient at $323 \mathrm{~K}$ are shown. The relationship between the VOC depletion factors $\left(\ln \left(\frac{[\mathrm{VOC}]_{0}}{[\mathrm{VOC}]}\right)\right)$ and $k$ shows an exponential cumulative distribution, likely due to the small concentrations of VOCs injected and the large range in $\mathrm{VOC}+\mathrm{OH}$ rate coefficients. The inset shows that it is possible to approximate the

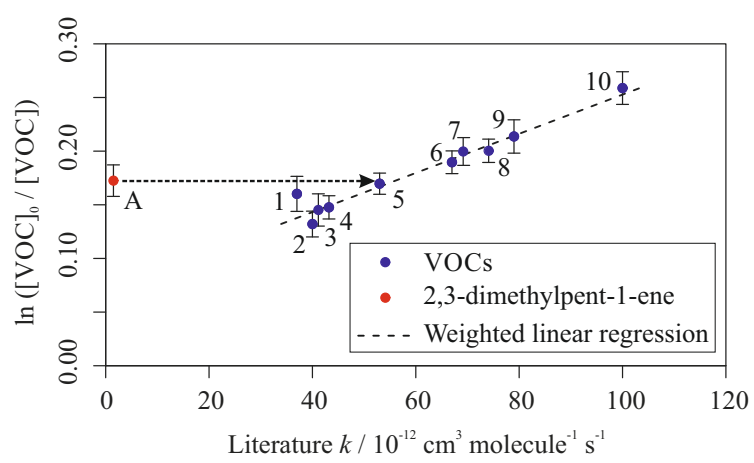

Figure 5. Relative rate plot for Mixture $2\left(\mathrm{OH}\right.$ reactivity is $30 \mathrm{~s}^{-1}$ ) at $295 \mathrm{~K}$. Compounds with a known rate coefficient are plotted using literature values. Error bars on the $y$ axis, equal to 1 standard error, are calculated by combining the standard error in peak areas for six lamp-off samples and six lamp-on samples. See Fig. S4 for a plot displaying $x$-axis error bars, which are not shown here due to reasons of clarity. A weighted linear fit was used to generate the slope with a value of $\mathrm{OH}_{\exp }=1.8( \pm 0.14) \times 10^{9}$ molecules $\mathrm{cm}^{-3} \mathrm{~s}$ and $R^{2}$ of 0.95 . Data for 2,3-dimethylpent-1-ene (A), which has no literature $k$ value, were not used in the calculation of the fit. Identities of VOCs: 1, 1-hexene; 2, 1-heptene; 3, 1-octene; 4, 1-nonene; 5, $\alpha$-pinene; 6, cyclopentene; 7, cyclohexene; 8 , cycloheptene; 9 , $\beta$-pinene; 10, isoprene.

rate coefficient for reactions with a $k$ value (at $323( \pm 10) \mathrm{K}$ ) of less than $30 \times 10^{-12} \mathrm{~cm}^{3}$ molecule ${ }^{-1} \mathrm{~s}^{-1}$ (corresponding to a depletion factor of less than 0.4) using linear regression. The rate coefficients estimated using both the curved relationship and linear regression are in very good agreement, within errors. The estimated $k$ values for many of the VOCs in Mixture 3 are also consistent with those in the literature (Table 3), suggesting that measurements at close to ambient atmospheric conditions are possible. One measurement stands out as contrasting with its literature value: that for $\beta$ ocimene, of $950( \pm 800) \times 10^{-12} \mathrm{~cm}^{3}$ molecule ${ }^{-1} \mathrm{~s}^{-1}$. This compound was at the higher end of the reactivity scale in Mixture 3, and hence small deviations in its depletion would lead to large variations in its measured value using the derived curved relationships. This is reflected in the comparatively large errors relative to the other VOCs in the mixture. Similar to $o$-xylene in Mixture 1, the results for this compound were removed from subsequent analyses.

Figure 8 shows an overall plot of all measured rate coefficients taken from Mixtures 1, 2 and 3 plotted against their literature reference counterparts. Solid data points are for measurements made at $294( \pm 2) \mathrm{K}$, whilst empty data points are for measurements conducted at the elevated reactor temperature of $323( \pm 10) \mathrm{K}$. The black solid line represents a $1: 1$ fit. Linear regression may be performed on the dataset in its entirety to determine the overall ability of this method for replicating literature rate coefficients. The gradient of this regression is $1.0( \pm 0.02)$, which suggests that this experimental technique is able to replicate the literature 


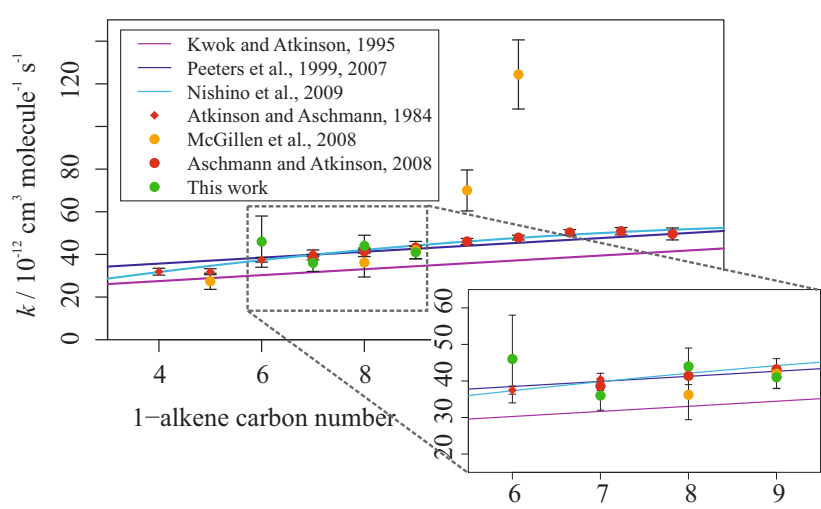

Figure 6. Plot showing experimentally derived (data points) and predicted SAR-derived (lines) $k$ values for 1-alkenes. Data from this study are shown in green; they are in good agreement with both previous experimentally derived results and with theoretical SARs.

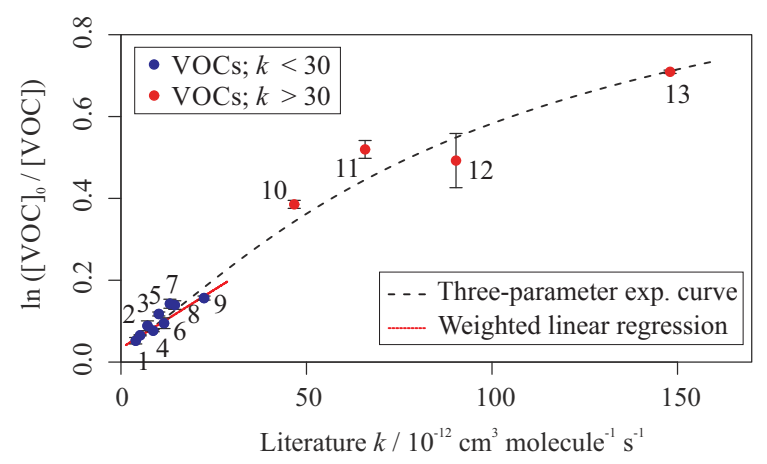

Figure 7. Relative rate plot for Mixture $3\left(\mathrm{OH}\right.$ reactivity is $\left.60 \mathrm{~s}^{-1}\right)$ at $323 \mathrm{~K}$. Compounds with a known rate coefficient are plotted using literature $k(323 \mathrm{~K})$ values. Error bars on the $y$ axis, equal to 1 standard error, are calculated by combining the standard error in peak areas for five lamp-off samples and five lamp-on samples. See Fig. S5 for a plot displaying $x$-axis error bars, which are not shown here for reasons of clarity. The black dashed line shows the relationship observed when VOC concentrations are low, modelled by an exponential cumulative distribution. A weighted linear fit was used to generate the red slope ( $R^{2}$ of 0.976$)$ for VOC with $k(323 \mathrm{~K})$ less than $30 \times 10^{-12} \mathrm{~cm}^{3}$ molecule $\mathrm{e}^{-1} \mathrm{~s}^{-1}$. Identities of VOCs: $1,2,2,3-$ trimethylbutane; 2 , toluene; $3, n$-heptane; $4, n$-octane; 5 , $n$-nonane; 6, $n$-decane; 7, cycloheptane; 8 , cyclooctane; 9 , naphthalene; 10 , $\alpha$-pinene; 11, $\beta$-pinene; 12, isoprene; 13, limonene.

exceptionally well. The vast majority of data lie well within an uncertainty in the literature of $25 \%$, shown by the grey shaded area. Outliers include 1-hexene at room temperature and 2,2,3-trimethylbutane and $n$-nonane at $323 \mathrm{~K}$.

Our studies suggest that a linear response between $\ln \left(\frac{[\mathrm{VOC}]_{0}}{[\mathrm{VOC}]}\right)$ and $k$ is best achieved when the VOCs in a mixture have a small range in $\mathrm{OH}$ rate coefficients (i.e. they react with $\mathrm{OH}$ at similar rates, with respect to each other). It appears that a non-linear response occurs when the mixing of VOCs and radicals is on similar timescales to the chemistry.
Therefore, mixtures that satisfy the above criteria are preferred for the estimation of novel rate coefficients, as demonstrated using Mixture 2. Whilst there is still a correlation between $\ln \left(\frac{[\mathrm{VOC}]_{0}}{[\mathrm{VOC}]}\right)$ and $k$ for mixtures which do not satisfy this criterion, the non-linearity makes the estimation of novel rate coefficients more challenging but still possible. These mixtures may therefore be better suited for highlighting inconsistencies within the current literature dataset for certain groups of compounds.

\subsection{Determination of new rate coefficients}

Mixture 2 contained the compound 2,3-dimethylpent-1-ene, for which we could find no literature rate coefficient measurements at the time of writing. 2,3-Dimethylpent-1-ene has been detected in emissions from certain tomato variants cultivated in Portugal (Figueira et al., 2014). Using a generalised version of Eq. (3), it is possible to estimate an experimentally derived room-temperature $\mathrm{OH}$ rate coefficient for this compound of $k=57( \pm 3) \times 10^{-12} \mathrm{~cm}^{3}$ molecule ${ }^{-1} \mathrm{~s}^{-1}$. As discussed earlier in Sect. 3, the error in this value is the statistical uncertainty calculated by combining the instrument error and the scatter in the data. However, the calculation of measurement uncertainty does not reflect the larger uncertainties, of up to $35 \%$, in the rate coefficients used as reference compounds and can therefore be considered an underestimation (lower limit) of the true uncertainty.

SARs are often used to predict rate coefficients for those compounds which do not have experimentally determined values. Three distinct SARs in the literature can be used to estimate a rate coefficient for 2,3-dimethylpent-1-ene. Using the methods outlined in Kwok and Atkinson (1995), Peeters et al. (1999, 2007) and Nishino et al. (2009), the rate coefficient for 2,3-dimethylpent-1-ene can be estimated as $k=55.0,63.1$ and $59.3 \times 10^{-12} \mathrm{~cm}^{3}$ molecule ${ }^{-1} \mathrm{~s}^{-1}$, respectively. These are all in good agreement with the experimental measurement made in this work.

Using the same method for Mixture $3, k$ values at $323 \mathrm{~K}$ for 20 compounds, as yet unmeasured at this temperature, can be calculated (Table 3). However, the straight line becomes increasingly less appropriate for estimating new rate coefficients at higher VOC depletion factors as the linear regression begins to deviate further from the data. Table 3 therefore also provides rate coefficients for all the compounds in Mixture 3 calculated using the equation of a curve, as opposed to the equation of the straight line, as shown in the inset of Fig. 7. This demonstrates that it is possible to derive new rate coefficients providing that there is a consistent relationship between VOC depletion factors and rate coefficients. In this way, using the curve, rate coefficients for a further five compounds with large depletions $\left(k>30 \times 10^{-12}\right)$ are estimated.

For the $\mathrm{OH}+$ monoterpene reactions, the rate coefficients determined in this work for Mixture 3 are in good agreement 


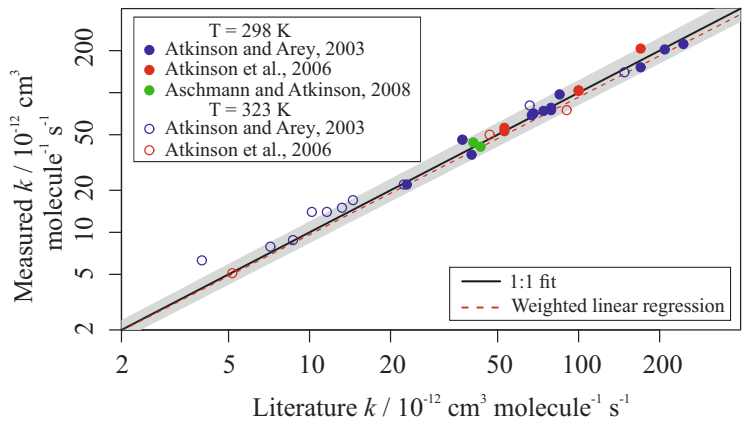

Figure 8. Measured VOC $+\mathrm{OH}$ rate coefficients plotted against literature $\mathrm{VOC}+\mathrm{OH}$ rate coefficients for all compounds measured as part of Mixtures 1, 2 and 3. Filled points represent data collected at room temperature $(294( \pm 2) \mathrm{K})$ and empty points represent data collected at the elevated temperature of $323( \pm 10) \mathrm{K}$. The grey shaded area demonstrates a $25 \%$ uncertainty in the $1: 1$ gradient; most data fall well within this bound. Data lying outside this bound include 1-hexene at room temperature and 2,2,3-trimethylbutane and $n$-nonane at $323 \mathrm{~K}$. Weighted linear regression analysis for the data yields a slope with equation $y=1.00( \pm 0.02) x+0.96( \pm 0.5)$ and an $R^{2}$ of 0.98 .

with rate coefficients derived by others at this temperature, within experimental errors and literature uncertainty. This demonstrates that this type of experiment is capable of assessing the temperature dependence of $\mathrm{VOC}+\mathrm{OH}$ rate coefficients. With the exception of 1-heptene, most of the estimated coefficients for $\mathrm{OH}+$ alkene reactions at $323 \mathrm{~K}$ are within $20 \%$ of the $298 \mathrm{~K}$ literature values; 1-heptene displays an anomalously low result. This reflects the temperaturedependent relationship described and observed in the literature for $\mathrm{OH}$ addition to alkenes and monoterpenes (Chuong et al., 2002; Kim et al., 2011).

Rate coefficients for the reaction between $\mathrm{OH}$ and 12 aromatic VOCs at $323 \mathrm{~K}$ are also estimated for the first time. We are also able to derive $323 \mathrm{~K}$ rate coefficients for the reaction between $\mathrm{OH}$ and three alkanes (2-methylheptane, 3methylheptane and ethylcyclohexane) for which we could find no room-temperature data in the literature at the time of writing. This highlights the pressing need for relevant temperature-dependent rate coefficient data.

\subsection{Determination of rate coefficients by ambient air sampling}

The use of synthetic gas mixtures places a limitation on the complexity of mixtures that can be introduced into the reactor and can only include compounds for which authentic standards or raw materials are available. The atmosphere represents an upper limit of mixture complexity, with regards to the VOC matrix, with the added benefit of containing VOCs which may not be readily available or readily synthesised, such as secondary or tertiary oxidation products. Should the determination of rate coefficients through ambi- ent atmospheric sampling be possible, comprehensive measurements of atmospherically relevant $\mathrm{VOC}+\mathrm{OH}$ reactions could be made.

Unfortunately, there are practical challenges associated with real atmospheric air sampling. First, the complexity of the atmosphere itself poses a problem and, whilst a mass spectrometer may aid with the identification of VOCs, single column gas chromatography may not always be enough to fully resolve all of the many individual compounds observed. The presence of additional oxidants and nitrogen oxides $\left(\mathrm{NO}_{x}\right)$ may also lead to further complications and interfere with the VOCs' concentrations during sampling and measurement. Many VOCs also exist in the atmosphere in concentrations that are orders of magnitude lower than those used in the synthetic gas mixtures outlined above, meaning that detection may be a problem, particularly after depletion using synthetic oxidants. Finally, the atmosphere is a dynamic mixture; the components and their concentrations are subject to constant change and as such, the experimental technique would need to account for these, often rapid, temporal fluctuations.

Some of these issues can be overcome by using a dualreactor instrument setup, allowing for two ambient air samples to be sampled simultaneously, as shown in Fig. 9. If $\mathrm{OH}$ is absent in both reactors, then identical samples should be observed. However, in practice, it is impossible to obtain two completely indistinguishable VOC measurements due to random but minor variations in sampling and later analysis. However, comparisons between the two reactors over time can be established to account for any systematic differences that are observed between the two systems.

$\mathrm{OH}$-initiated reactions can be induced in one of the reactors whilst the other is sampled simultaneously in the absence of synthetic oxidants. This allows for the construction of a dataset of VOC concentrations with and without synthetic $\mathrm{OH}$ radicals present. Unlike for synthetic mixtures, where VOC concentrations from multiple samples were averaged before processing using Eq. (3), the natural variability in atmospheric VOC mixing ratios dictates that a $\ln \left(\frac{[\mathrm{VOC}]_{0}}{[\mathrm{VOC}]}\right)$ value must be calculated for each VOC for each dual sample.

Using this experimental technique for ambient air analysis, VOC reactivity was analysed at the Wolfson Atmospheric Chemistry Laboratories at the University of York, a suburban site in York, United Kingdom, during the period 6-10 June 2014. The sampling site was approximately $200 \mathrm{~m}$ from a local commuter road, $1.5 \mathrm{~km}$ from a dual carriageway and in close proximity to a small area of woodland consisting primarily of oak and sycamore trees. There was a large dynamic range in the concentrations of VOCs observed; some species, for instance, styrene, experienced large degrees of scatter, due in part to very low ambient mixing ratios (16 parts per trillion by volume; pptv). A total of $5 \mathrm{ppb}$ of ozone was also detected at the end of the reactors. This could be attributed to the presence of non-synthetic oxidants and $\mathrm{NO}_{x}$ but is likely 


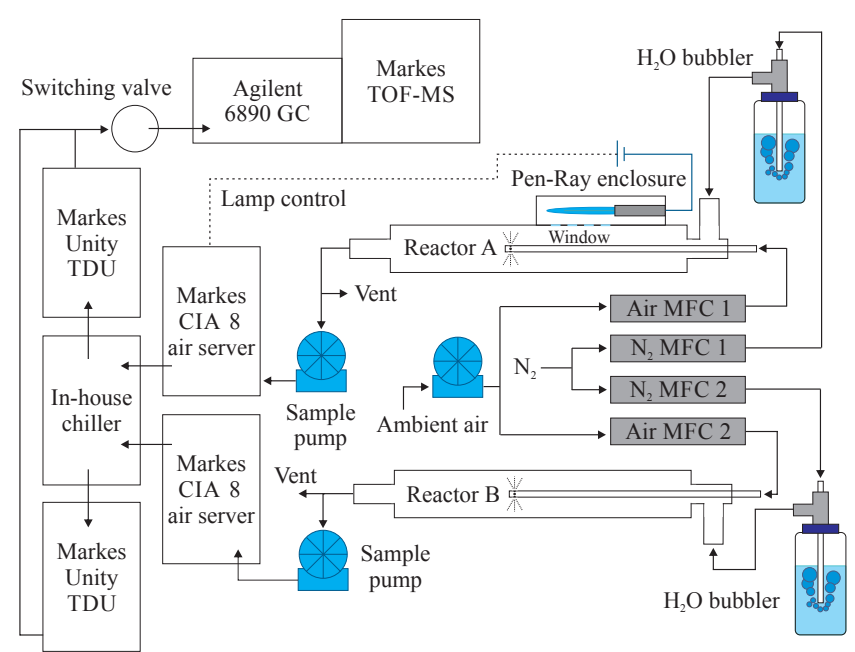

Figure 9. Schematic of the $\mathrm{OH}$ reactor configuration used for sampling ambient air VOC. CIA 8 is the air server and canister interface accessory; GC is the gas chromatograph; MFC is the mass flow controller; TOF-MS is the time-of-flight mass spectrometer; TDU is the thermal desorption unit.

to be the ambient ozone sampled from outside that made it through the heated sample lines. At this concentration, given the rate of reaction between $\mathrm{O}_{3}$ and all the compounds analysed, it is unlikely that the $\mathrm{O}_{3}$ would have a significant impact on the degradation of any species within the reactor. Indeed, even for the reaction between $\mathrm{O}_{3}$ and styrene, which proceeds at $1.70 \times 10^{-17} \mathrm{~cm}^{3}$ molecule ${ }^{-1} \mathrm{~s}^{-1}$ (Atkinson and Arey, 2003), the depletion by $\mathrm{O}_{3}$ accounts for less than $1 \%$ of its total depletion (see Table S2).

A total of 23 VOCs (including alkanes, alkenes, aromatics, isoprene, monoterpenes, naphthalene, ethyl acetate and dichloromethane - see Table 4) were positively identified from the GC-MS data. The vast majority of identified VOCs have very slow rate coefficients for reaction with $\mathrm{O}_{3}$, with a maximum of $1 \times 10^{-20} \mathrm{~cm}^{3}$ molecule ${ }^{-1} \mathrm{~s}^{-1}$ for the alkanes and alkylbenzenes (Atkinson and Arey, 2003). Of the 23 identified compounds, four monoterpenes ( $\alpha$-pinene, $\beta$ pinene, 3-carene and limonene) react relatively fast with both $\mathrm{OH}$ and $\mathrm{O}_{3}$ (see Table 4), and their concentrations were decreased to below the limit of detection for the "lampon" samples. These four compounds were therefore removed from subsequent analyses.

Depletion factors for the eight identified compounds which have $323 \mathrm{~K}$ literature rate coefficients are shown in Fig. 10 in blue. There is a clear linear relationship, shown by the black dashed line, between the depletion factors for these eight compounds and their rate coefficient for reaction with $\mathrm{OH}$. However, a significant section of the plot lacks literature data for comparison. It may therefore be beneficial, in future work deriving rate coefficients from real air samples, to synthetically spike the air with a range of reference compounds whose rate coefficients are accurately known, in order to en-

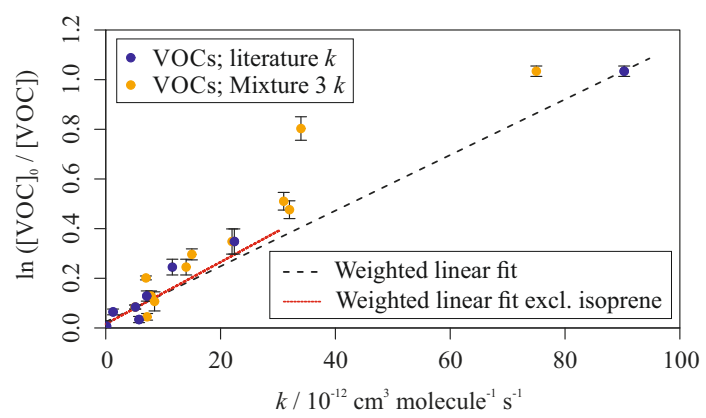

Figure 10. Relative rate plot for ambient air analysis. Compounds with a known rate coefficient are plotted using literature values at $323 \mathrm{~K}$. A weighted linear fit of these data was used to generate the black dashed slope with an $R^{2}$ of 0.98 . A second weighted linear fit, excluding isoprene, is shown by the red dashed slope $\left(R^{2}\right.$ of 0.71$)$. Some of the compounds do not have literature rate coefficients at $323 \mathrm{~K}$ but were measured at this temperature elsewhere in this paper (see Table 3). Compounds with a rate coefficient derived from Mixture 3 relative rate studies are also plotted (in yellow) to compare between the synthetic mixture and ambient air results. Error bars on the $y$ axis, equal to 2 standard errors, are calculated using the standard deviation in depletion factors for each VOC across all samples. Error bars on the $x$ axis are not shown but are typically large (up to $35 \%$ ).

sure that the best possible correlation between depletion factor and literature rate coefficient can be generated across the desired range. In the absence of this, and to aid in the clarification of the linear relationship between rate coefficients and depletion factors, seven compounds, whose rate coefficients were derived in earlier studies using synthetic gas mixtures (Mixture 3), are also plotted in yellow. A total of six of these compounds are in good agreement with the linear correlation derived using the literature, within experimental error. A linear fit to the $323 \mathrm{~K}$ data which excludes isoprene, the fastest-reacting observed VOC, is shown by the red dashed line. This linear regression gives a slightly better fit to the data derived from the synthetic gas mixture.

The relative rate results for 19 compounds are provided in Table 4. Except for $n$-hexane and dichloromethane, the $323 \mathrm{~K}$ rate coefficients for six compounds (benzene, isoprene, $n$ heptane, $n$-decane, naphthalene and toluene) are in reasonable agreement to comparable rate coefficients in the literature. Two compounds (dichloromethane and ethyl acetate) yield negative rate coefficients as the depletions in their concentrations were generally smaller than the instrument noise. New rate coefficients, at $323 \mathrm{~K}$, for three compounds (dodecane, styrene and tridecane) are also derived for the first time.

The ambient air derived rate coefficient for the $\mathrm{OH}+3-$ ethyltoluene reaction is almost twice as large as that determined using the synthetic mixture, which itself was anomalously larger than the $298 \mathrm{~K}$ literature equivalent. Many $k$ values determined using ambient air sampling are systematically larger than those in the literature for reactions at $298 \mathrm{~K}$. 
Table 4. Results of relative rate experiments, with literature data, for VOCs in the ambient air analysis, ordered by ambient air measured $k$ value.

\begin{tabular}{|c|c|c|c|c|}
\hline Compound & $\begin{array}{r}\text { Ambient air measured } \\
k(323 \mathrm{~K}) / 10^{-12} \mathrm{~cm}^{3} \\
\text { molecule }^{-1} \mathrm{~s}^{-1}\end{array}$ & $\begin{array}{r}\text { Synthetic mixture } \\
\text { measured } k(323 \mathrm{~K}) / \\
10^{-12} \mathrm{~cm}^{3} \text { molecule } \mathrm{s}^{-1}\end{array}$ & $\begin{array}{r}\text { Literature } k(323 \mathrm{~K}) / \\
10^{-12} \mathrm{~cm}^{3} \text { molecule } \mathrm{s}^{-1} \mathrm{~s}^{-1}\end{array}$ & $\begin{array}{r}\text { Literature } k(298 \mathrm{~K}) / \\
10^{-12} \mathrm{~cm}^{3} \text { molecule }^{-1} \mathrm{~s}^{-1}\end{array}$ \\
\hline Tridecane & $140 \pm 10$ & & & $15.1 \pm 3.8^{\mathrm{a}}$ \\
\hline Isoprene & $90 \pm 3$ & $75 \pm 8$ & $90\left(\begin{array}{l}+33 \\
-24\end{array}\right)^{\mathrm{b}}$ & $100\left({ }_{-13}^{+15}\right)^{\mathrm{b}}$ \\
\hline Styrene & $81 \pm 7$ & & & $58 \pm 12^{\mathrm{a}}$ \\
\hline 3-Ethyltoluene & $70 \pm 5$ & $34 \pm 1$ & & $19 \pm 7^{\mathrm{a}}$ \\
\hline Dodecane & $58 \pm 8$ & & & $13 \pm 3^{\mathrm{a}}$ \\
\hline 1,2,3-Trimethylbenzene & $44 \pm 4$ & $31 \pm 1$ & & $33 \pm 8^{\mathrm{a}}$ \\
\hline 1,2,4-Trimethylbenzene & $40 \pm 4$ & $32 \pm 1$ & & $33 \pm 8^{\mathrm{a}}$ \\
\hline Naphthalene & $29 \pm 5$ & $22 \pm 1$ & $22.4^{\mathrm{a}}$ & $23 \pm 6^{\mathrm{a}}$ \\
\hline 2-Ethyltoluene & $24 \pm 3$ & $15 \pm 1$ & & $12 \pm 4^{\mathrm{a}}$ \\
\hline$n$-Decane & $20 \pm 3$ & $14 \pm 1$ & $12\left(\begin{array}{c}+2 \\
-1.9\end{array}\right)^{\mathrm{a}}$ & $11 \pm 2^{\mathrm{a}}$ \\
\hline Ethylbenzene & $16 \pm 2$ & $7.0 \pm 1$ & & $7.0 \pm 2^{\mathrm{a}}$ \\
\hline$n$-Heptane & $9.3 \pm 2.2$ & $7.9 \pm 0.5$ & $7.2\left(\begin{array}{c}+2 \\
-1.6\end{array}\right)^{\mathrm{a}}$ & $6.8 \pm 1.4^{\mathrm{a}}$ \\
\hline$n$-Propylbenzene & $7.4 \pm 3.0$ & $8.5 \pm 0.5$ & & $5.8 \pm 1.5^{\mathrm{a}}$ \\
\hline Toluene & $5.4 \pm 1.2$ & $5.1 \pm 0.3$ & $5.2\left(\begin{array}{c}+4 \\
-2\end{array}\right)^{\mathrm{a}}$ & $5.6\left(\begin{array}{l}+1.5 \\
-1.2\end{array}\right)^{b}$ \\
\hline Benzene & $3.6 \pm 1.1$ & & $1.3 \pm 0.4^{\mathrm{a}}$ & $1.2 \pm 0.2^{\mathrm{a}}$ \\
\hline Isopropylbenzene & $1.8 \pm 0.8$ & $7.2 \pm 1.0$ & & $5.8 \pm 1.2^{\mathrm{a}}$ \\
\hline$n$-Hexane & $0.9 \pm 0.5$ & & $5.8 \pm 0.5^{\mathrm{a}}$ & $5.2 \pm 1.3^{\mathrm{a}}$ \\
\hline Ethyl acetate & $-0.13 \pm 0.04$ & & & $1.7 \pm 0.3^{\mathrm{c}}$ \\
\hline Dichloromethane & $-1.5 \pm 0.9$ & & $0.13\left(\begin{array}{l}+0.07 \\
-0.05\end{array}\right)^{b}$ & $0.1\left({ }_{-0.02}^{+0.03}\right)^{\mathrm{b}}$ \\
\hline
\end{tabular}

${ }^{\mathrm{a}}$ Atkinson and Arey (2003). ${ }^{\mathrm{b}}$ Atkinson et al. (2006) (see also IUPAC Task Group on Atmospheric Chemical Kinetic Data Evaluation website - http://iupac.pole-ether.fr). ${ }^{\mathrm{c}}$ Calvert et al. (2011).

This is likely due to the increased complexity of sampling and analysing ambient air when compared with synthetic gas mixtures (as discussed above) and the large range in terms of both reactivity and concentration in the compounds sampled. However, it is clearly still possible to estimate reasonable rate coefficients, albeit with higher uncertainties, for most of the ambient observed compounds. The use of this technique is therefore especially useful for VOCs which are not commercially available or easily synthesised or isolated, such as the oxidation products of common atmospheric species.

\section{Atmospheric implications and conclusions}

We have demonstrated here a simple and versatile method for measuring relative rate coefficients for reactions of $\mathrm{OH}$ with multiple VOCs simultaneously, based upon the wellestablished relative rate kinetic technique. The method builds upon that used to estimate the contribution of unidentified VOCs to OH reactivity (Kato et al., 2011). Three synthetic gas mixtures have been used with this technique, covering a broad range in VOC functionality and in rates of reaction with $\mathrm{OH}$ radicals. Additionally, these mixtures have been studied at different temperatures, showing that this method could be applied to quickly generate temperature-dependant Arrhenius expressions for multiple VOCs with only very simple, minor modifications to the current setup. Conse- quently, we have been able to estimate novel rate coefficients at $323 \mathrm{~K}$ for a total of 28 atmospherically relevant VOCs, including three that have no measurements at room temperature (2-methylheptane, 3-methylheptane and ethylcyclohexane). We have also been able to provide results which are in good agreement with the only previously recorded measurements for the reactions between $\mathrm{OH}$ and $\gamma$-terpinene and $\mathrm{OH}$ and cycloheptene, along with various other VOCs for which few results were previously available.

We have shown that this method can produce rate coefficients for VOCs, the $\mathrm{OH}$ kinetics of which have not been investigated to date by providing the first measurement of the $\mathrm{OH}+2,3$-dimethylpent-1-ene reaction, at room temperature, of $k=5.7( \pm 0.3) \times 10^{-11} \mathrm{~cm}^{3}$ molecule ${ }^{-1} \mathrm{~s}^{-1}$. Using an approximate atmospheric concentration of $\mathrm{OH}$, of $1 \times 10^{6}$ molecules $\mathrm{cm}^{-3}$, gives an estimated $\mathrm{OH}$ lifetime for 2,3dimethylpent-1-ene of $4.9 \mathrm{~h}$. This corresponds to 2.5 times its loss rate with respect to $\mathrm{O}_{3}$ (estimated using an approximate atmospheric $\mathrm{O}_{3}$ concentration of $30 \mathrm{ppb}$ and the SAR provided in King et al., 1999).

We have also shown that using a dual-reactor setup allows for the derivation of rate coefficients via ambient air sampling. Rate coefficients for six compounds were shown to be in reasonable agreement with the literature. Additionally, a further three new rate coefficients were measured at $323 \mathrm{~K}$ using this method of ambient air sampling (dodecane, 
styrene and tridecane). Further improvements in analytical detection limits and chromatographic resolution would allow the method to be extended to more VOCs, including less volatile organics. By using a TOF-MS, there is also the possibility of retrospectively determining $\mathrm{OH}+\mathrm{VOC}$ reaction rates, should a species be deemed important in the future.

In summary, this technique represents a significant breakthrough in the measurement of atmospherically relevant oxidation kinetics. The throughput of target compounds has been improved dramatically with respect to the base relative rate technique, which will allow for the rapid development of experimentally derived measurements for homologous series of multifunctional, long-chain and branched systems, as demonstrated by that for the 1-alkenes in this work. The possibility of conducting temperature-dependent studies will allow for a significant broadening of our knowledge in this area. The technique could also be adapted for use with $\mathrm{Cl}$ or $\mathrm{NO}_{3}$ radicals, for which oxidative kinetic measurements are severely limited in the literature. Additionally, the use of ambient air with this technique demonstrates its versatility and highlights the possibility of measuring reaction rates for difficult-to-synthesise, or currently unidentified, VOCs. Finally, the rate coefficients for reactions of $\mathrm{OH}$ with unidentified VOCs in the atmosphere can be measured using this method. If the concentrations of these species can be estimated, then the method would enable missing $\mathrm{OH}$ reactivity to be quantified.

Data availability. Raw data are available at https://doi.org/10.15124/93f81821-c151-4a4a-be8b-af394d3f1059 (Dillon and Hamilton, 2018).

\section{The Supplement related to this article is available online at https://doi.org/10.5194/acp-18-4039-2018-supplement.}

Author contributions. ACL, ARR, DEH, JFH and LKW planned the overall project; DEH, LJC, JFH and TJD designed experiments; DRC, GAB, LKW, NR, RED and TI conducted initial experiments; JTS, RTL and FCW conducted later experiments; JTS and RTL performed the analysis; JTS, RTL and TJD prepared the manuscript with contributions from all authors.

Competing interests. The authors declare that they have no conflict of interest.

Acknowledgements. The authors would like to thank Mat Evans for his contributions to an earlier iteration of this work, Mike Newland for many useful discussions, Martyn Ward for his excellent technical support throughout the project, and Abigail Mortimer,
Chris Mortimer and Chris Rhodes for their assistance in the respective glass, mechanical and electronic workshops. We are grateful to the Natural Science Research Council (NERC) for funding this work under grant numbers NE/I012737/1, NE/I014616/1 and NE/J008532/1. We would also like to thank NERC for the provision of a research studentship (Danny R. Cryer) and the funding of a PhD as part of the SPHERES DTP scheme (Jacob T. Shaw).

Edited by: Sergey A. Nizkorodov

Reviewed by: three anonymous referees

\section{References}

Aschmann, S. M. and Atkinson, R.: Rate constants for the gasphase reactions of $\mathrm{OH}$ radicals with $E$-7-tetradecene, 2-methyl1-tridecene and the $\mathrm{C}_{7}-\mathrm{C}_{14}$ 1-alkenes at $295 \pm 1 \mathrm{~K}$, Phys. Chem. Chem. Phys., 10, 4159-4164, https://doi.org/10.1039/B803527J, 2008.

Atkinson, R.: Kinetics and mechanisms of the gas-phase reactions of the hydroxyl radical with organic compounds under atmospheric conditions, Chem. Rev., 86, 69-201, https://doi.org/10.1021/cr00071a004, 1986.

Atkinson, R. and Arey, J.: Atmospheric degradation of volatile organic compounds, Chem. Rev., 103, 4605-4638, https://doi.org/10.1021/cr0206420, 2003.

Atkinson, R., Baulch, D. L., Cox, R. A., Crowley, J. N., Hampson, R. F., Hynes, R. G., Jenkin, M. E., Rossi, M. J., Troe, J., and IUPAC Subcommittee: Evaluated kinetic and photochemical data for atmospheric chemistry: Volume II - gas phase reactions of organic species, Atmos. Chem. Phys., 6, 3625-4055, https://doi.org/10.5194/acp-6-3625-2006, 2006.

Braure, T., Bedjanian, Y., Romanias, M. N., Morin, J., Riffault, V., Tomas, A., and Coddeville, P.: Experimental study of the reactions of limonene with $\mathrm{OH}$ and $\mathrm{OH}$ radicals: kinetics and products, J. Phys. Chem. A, 118, 9482-9490, https://doi.org/10.1021/jp507180g, 2014.

Burke, S.: Missing values, outliers, robust statistics \& non-parametric methods, LC.GC Europe Online Supplement, statistics and data analysis, available at: https://www.webdepot.umontreal.ca/Usagers/sauves/ MonDepotPublic/CHM3103/LCGCEurBurke2001-4de4.pdf (last access: 21 August 2017), 19-24, 1998.

Burkholder, J. B., Abbatt, J. P. D., Barnes, I., Roberts, J. M., Melamed, M. L., Ammann, M., Bertram, A. K., Cappa, C. D., Carlton, A. G., Carpenter, L. J., Crowley, J. N., Dubowski, Y., George, C., Heard, D. E., Herrmann, H., Keutsch, F. N., Kroll, J. H., McNeill, V. F., Ng, N. L., Nizkorodov, S. A., Orlando, J. J., Percival, C. J., Picquet-Varrault, B., Rudich, Y., Seakins, P. W., Surratt, J. D., Tanimoto, H., Thornton, J. A., Tong, Z., Tyndall, G. S., Wahner, G. S., Weschler, C. J., Wilson, K. R., and Ziemann, P. J.: The essential role for laboratory studies in atmospheric chemistry, Environ. Sci. Technol., 51, 2519-2528, https://doi.org/10.1021/acs.est.6b04947, 2017.

Calvert, J. G., Atkinson, R., Kerr, J. A., Madronich, S., Moortgat, G. K., Wallington T. J., and Yarwood, G.: The mechanisms of atmospheric oxidation of the alkenes, Oxford University Press, New York, 2000. 
Calvert, J. G., Atkinson, R., Becker, K. H., Kamens, R. M., Seinfeld, J. H., Wallington, T. J., and Yarwood, G.: The mechanisms of atmospheric oxidation of aromatic hydrocarbons, Oxford University Press, New York, 2002.

Calvert, J. G., Mellouki, A., Orlando, J. J., Pilling, M. J., and Wallington, T. J.: The mechanisms of atmospheric oxidation of the oxygenates, Oxford University Press, New York, 2011.

Chuong, B., Davis, M., Edwards, M., and Stevens, P. S.: Measurements of the kinetics of the $\mathrm{OH}+\alpha$-pinene and $\mathrm{OH}+\beta$-pinene reactions at low pressure, Int. J. Chem. Kinet., 34, 300-308, 2002.

Cryer, D. R.: Measurements of hydroxyl radical reactivity and formaldehyde in the atmosphere, $\mathrm{PhD}$ thesis, University of Leeds, 2016.

Di Carlo, P., Brune, W. H., Martinez, M., Harder, H., Lesher, R., Ren, X. R., Thornberry, T., Carroll, M. A., Young, V., Shepson, P. B., Riemer, D., Apel, E., and Campbell, C.: Missing OH reactivity in a forest: evidence for unknown reactive biogenic VOC, Science, 304, 722-725, 2004.

Dillon, T. J. and Hamilton, J. F.: Datasets for the publication: "A self-consistent, multi-variate method for the determination of gas-phase rate coefficients, applied to reactions of atmospheric VOCs and the hydroxyl radical", York Research Database, University of York, https://doi.org/10.15124/93f81821-c151-4a4abe8b-af394d3f1059, 2018.

Dunmore, R. E., Hopkins, J. R., Lidster, R. T., Lee, J. D., Evans, M. J., Rickard, A. R., Lewis, A. C., and Hamilton, J. F.: Diesel-related hydrocarbons can dominate gas phase reactive carbon in megacities, Atmos. Chem. Phys., 15, 9983-9996, https://doi.org/10.5194/acp-15-9983-2015, 2015.

Edwards, P. M., Evans, M. J., Furneaux, K. L., Hopkins, J., Ingham, T., Jones, C., Lee, J. D., Lewis, A. C., Moller, S. J., Stone, D., Whalley, L. K., and Heard, D. E.: OH reactivity in a South East Asian tropical rainforest during the Oxidant and Particle Photochemical Processes (OP3) project, Atmos. Chem. Phys., 13, 9497-9514, https://doi.org/10.5194/acp-13-9497-2013, 2013.

Figueira, J., Câmara, H., Pereira, J., and Câmara, J. S.: Evaluation of volatile metabolites as markers in Lycopersicon esculentum L. cultivars discrimination by multivariate analysis of headspace solid phase microextraction and mass spectrometry data, Food Chem., 145, 653-663, 2014.

Finlayson-Pitts, B. J. and Pitts Jr., J. N.: Tropospheric air pollution: ozone, airborne toxics, polycyclic aromatic hydrocarbons, and particles, Science, 276, 1045-1051, 1997.

Gaona-Colmán, E., Blanco, M. B., Barnes, I., and Teruel, M. A.: Effect of $\mathrm{NO}_{x}$ on product yields and Arrhenius parameters of gas-phase oxidation of $\beta$-ocimene initiated by $\mathrm{OH}$ radicals, RSC Adv., 6, 92795-92803, https://doi.org/10.1039/c6ra26656h, 2016.

Goldstein, A. H. and Galbally, I. E.: Known and unexplored organic constituents in the Earth's atmosphere, Environ. Sci. Technol., 41. 1514-1521, https://doi.org/10.1021/es072476p, 2007.

Guenther, A. G.: The contribution of reactive carbon emissions from vegetation to the carbon balance of terrestrial ecosystems, Chemosphere, 49, 837-844, https://doi.org/10.1016/S00456535(02)00384-3, 2002

Hites, R. A. and Turner, A. M.: Rate constants for the gasphase $\beta$-myrcene $+\mathrm{OH}$ and isoprene $+\mathrm{OH}$ reactions as a function of temperature, Int. J. Chem. Kinet., 41, 407-413, https://doi.org/10.1002/kin.20413, 2009.

Kato, S., Sato, T., and Kajii, Y.: A method to estimate the contribution of unidentified VOC to OH reactivity, Atmos. Environ., 45, 5531-5539, https://doi.org/10.1016/j.atmosenv.2011.05.074, 2011.

Kim, D., Stevens, P. S., and Hites, R. A.: Rate constants for the gasphase reactions of $\mathrm{OH}$ and $\mathrm{O}_{3}$ with $\beta$-ocimene, $\beta$-myrcene, and $\alpha$ - and $\beta$-farnesene as a function of temperature, J. Phys. Chem. A, 115, 500-506, https://doi.org/10.1021/jp111173s, 2011.

King, M. D., Canosa-Mas, C. E., and Wayne, R. P.: A structureactivity relationship (SAR) for predicting rate constants for the reaction of $\mathrm{NO}_{3}, \mathrm{OH}$ and $\mathrm{O}_{3}$ with monoalkenes and conjugated dienes, Phys. Chem. Chem. Phys., 1, 2239-2246, 1999.

Kovacs, T. A., Brune, W. H., Harder, H., Martinez, M., Simpas, J. B., Frost, G. J., Williams, E., Jobson, T., Stroud, C., Young, V., Fried, A., and Wert, B.: Direct measurements of urban $\mathrm{OH}$ reactivity during Nashville SOS in summer 1999, J. Environ. Monitor., 5, 68-74, 2003.

Kwok, E. S. C. and Atkinson, R.: Estimation of hydroxyl radical reaction rate constants for gas-phase organic compounds using a structure-reactivity relationship: an update, Atmos. Environ., 29, 1685-1695, https://doi.org/10.1016/1352-2310(95)00069-B, 1995.

Lewis, A. C., Carslaw, N., Marriott, P. J., Kinghorn, R. M., Morrison, R., Lee, A. L., Bartle, K. D., and Pilling, M. J.: A larger pool of ozone-forming carbon compounds in urban atmospheres, Nature, 405, 778-781, https://doi.org/10.1038/35015540, 2000.

Lidster, R. T., Hamilton, J. F., Lee, J. D., Lewis, A. C., Hopkins, J. R., Punjabi, S., Rickard, A. R., and Young, J. C.: The impact of monoaromatic hydrocarbons on $\mathrm{OH}$ reactivity in the coastal UK boundary layer and free troposphere, Atmos. Chem. Phys., 14, 6677-6693, https://doi.org/10.5194/acp-14-6677-2014, 2014.

McGillen, M. R., Percival, C. J., Shallcross, D. E., and Harvey, J. N.: Is hydrogen abstraction an important pathway in the reaction of alkenes with the $\mathrm{OH}$ radical?, Phys. Chem. Chem. Phys., 9, 4349-4356, 2007.

Nishino, N., Arey, J., and Atkinson, R.: Rate constants for the gasphase reactions of $\mathrm{OH}$ radicals with a series of $\mathrm{C}_{6}-\mathrm{C}_{14}$ alkenes at $299 \pm 2$ K, J. Phys. Chem. A, 113, 852-857, 2009.

Peeters, J., Vandenberk, S., Piessens, E., and Pultau, V.: H-atom abstraction in reactions of cyclic polyalkenes with $\mathrm{OH}$, Chemosphere, 38, 1189-1195, 1999.

Peeters, J., Boullart, W., Pultau, V., Vandenberk, S., and Vereecken, L.: Structure-activity relationships for the addition of $\mathrm{OH}$ to (poly)alkenes: site specific and total rate constants, J. Phys. Chem. A, 111, 1618-1631, 2007.

Pilling, M. J. and Seakins, P. W.: Reaction Kinetics, Oxford University Press, New York, United States, 27-57, 1995.

Rogers, J. D.: Rate constant measurements for the reaction of the hydroxyl radical with cyclohexene, cyclopentene, and glutaraldehyde, Environ. Sci. Technol., 23, 177-181, https://doi.org/10.1021/es00179a006, 1989.

Sinha, V., Williams, J., Crowley, J. N., and Lelieveld, J.: The Comparative Reactivity Method - a new tool to measure total $\mathrm{OH}$ Reactivity in ambient air, Atmos. Chem. Phys., 8, 2213-2227, https://doi.org/10.5194/acp-8-2213-2008, 2008. 
Yang, Y., Shao, M.., Wang, X., Nölscher, A. C., Kessel, S., Guenther, A., and Williams, J.: Towards a quantitative understanding of total OH reactivity: A review, Atmos. Environ., 134, 147-161, 2016.
Ziemann, P. J. and Atkinson, R.: Kinetics, products, and mechanisms of secondary organic aerosol formation, Chem. Sci. Rev., 41, 6582-6605, https://doi.org/10.1039/C2CS35122F, 2012. 